\title{
A NEW METHOD TO DETERMINE ELASTO-PLASTIC $J$-INTEGRAL FOR STEEL PIPES WITH LONGITUDINAL SEMI-ELLIPTICAL SURFACE CRACKS
}

\author{
Weigang Wang ${ }^{1}$, Wei Yang ${ }^{2}$, Chun-Qing $\mathrm{Li}^{1, *}$ and Shangtong Yang ${ }^{3}$ \\ ${ }^{1}$ School of Engineering, RMIT University, Melbourne, 3001, Australia \\ ${ }^{2}$ Faculty of Architecture, Building and Planning, The University of Melbourne, Australia \\ ${ }^{3}$ Faculty of Engineering, University of Strathclyde, Glasgow, G1 1XQ, United Kingdom
}

\section{ABSTRACT}

Steel pipes have been widely used in the water and petroleum industries where crack-like flaws have long been recognised as a major cause of their failures. This paper intends to develop a new method for determining the elasto-plastic $J$-integral of cracked pipes made of all types of steel. A solution to elasto-plastic $J$-integrals is derived for external longitudinal semi-elliptical surface cracks in pressurised steel pipes. A meshing technique is developed in the detailed threedimensional finite element analysis that incorporates the mixed types of quadratic tetrahedron and hexahedron elements. The developed method is verified with detailed finite element results. It is found in the paper that the general trend of normalised fully plastic $J$-integral changes with the change of crack depths and aspect ratios, and the magnitude of normalised fully plastic $J$ integrals can be significantly affected by material properties and pipe dimensions. The developed method can provide a useful tool for the failure assessment of pressurized steel pipes, allowing for a wide range of pipe dimensions, crack geometries and material properties.

\section{KEYWORDS}

Elasto-plastic $J$; thin-wall pipes; surface crack; 3D finite element; yielding plateau.

*Corresponding author, Professor Chun-Qing Li, email: chunqing.li@rmit.edu.au 


\section{INTRODUCTION}

The surface cracks have been identified as the main cause of failures for pressurised steel pipes. To quantify the stress state in the vicinity of a crack front, a number of researchers, e.g., Anderson (2017), Li and Yang (2012), Laham (1999), and Raju and Newman (1982) etc., have developed various solutions to stress intensity factors (SIF) for the cracked pipes, based on linear elastic fracture mechanics (LEFM) (Fu et al. 2019 and Wang et al. 2019). As it is known, SIF solutions are only valid for linear elastic materials or ductile materials under small-scale yielding condition, where the deformation of the material is predominately linear elastic. For pipes made of ductile or elasto-plastic materials, such as steel pipes, however, large plastic deformation can occur around a crack before the fracture initiates. In this situation, the stresses around the crack-tip are relaxed, and as a result, the SIF solutions derived from LEFM become inapplicable in determining the real stress-state around the crack. To overcome this problem, the elasto-plastic fracture mechanics has been developed (Anderson 2017), in which $J$-integral, among others, is a key parameter.

A review of published literature (e.g., Surh et al. 2017; Cho et al. 2011; Kim et al. 2004; Lei 2004; Kumar et al. 1984,1981) shows that considerable research has been undertaken to determine the $J$-integral for cracked pipes made of ductile or elastoplastic materials. For example, the solutions to $J$-integral for through-wall cracks and continuous (full-length) partthrough cracks in pipes were developed by the General Electric/Electric Power Research Institute (GE/EPRI) based on shell line-spring finite element (FE) models. The results of these solutions are well documented in EPRI-NP-1931 (Kumar et al. 1981) and EPRI-NP-3607 (Kumar et al. 1984). Other researchers, e.g., Park et al. (2019), Surh et al. (2017), Jeong et al. (2016) and Kim et al. (2001, 2002a, 2002b), further extended the existing solutions to $J$-integral for through-wall cracks in pipes under various loading conditions. As the crack-like defects 
51 detected in real pipes are usually semi-circular or semi-elliptical (Bloom 1983), most studies (e.g., Liu et al. 2018, Cho et al. 2011 and Kim et al.(2004) investigated the $J$-integral for semielliptical cracks with focus on circumferential cracks.

Further review of the literature suggests that there is a lack of solutions to $J$-integral for the external longitudinal semi-elliptical surface cracks (LSSC) in steel pipes. The reason is that most solutions to $J$-integral were developed for the nuclear steel pipes (Østby et al. 2005), whereby circumferential cracks are considered more significant than the longitudinal ones in their risk assessment (Kim et al. 2003). The external LSSC, however, is one of the most commonly encountered defects in buried steel pipes used for water, oil and gas transport (Wang et al. 2019 and Makar et al. 2001), which is often initiated by corrosion pits (Koduru and Nessim 2017). As it is known a solution to elasto-plastic $J$-integral for circumferential cracks in pipes is not straightforward to that for longitudinal cracks. More sophisticated modelling and meshing techniques in 3D finite element analysis (FEA) is required due to the 3-D nature of LSSC.

Some researchers, e.g., Wang (2006), Lei (2004), Kim et al. (2002c) and Yagawa (1993) have derived solutions to the elasto-plastic $J$-integral for semi-elliptical surface cracks in plates under tension. They suggested that these solutions could be used for estimating the $J$-integral for structural design and assessment, leading to ultimate failures. The underestimate of $J$-integral walls (Kiefner et al. 1973), which can produce additional stress near the crack tip, leading to the increase of $J$-integral. Evidently there is a clear need to develop new solutions to $J$-integral for external LSSC in steel pipes. 
The review also shows that most of current research (e.g., Park et al. 2019; Surh et al. 2017; Cho et al. 2011; Kim et al. 2004) used the reference stress (RS) method to estimate the elastoplastic $J$ integral for cracked structures. This is because the GE/EPRI method cannot determine the $J$-integral accurately when the materials do not follow stress-strain law of Ramberg-Osgood (R-O) (EDF Energy 2015). The stress-strain curve for those materials which follow the R-O model does not show a clear yielding plateau. Figure 1 shows the difference in stress-strain curves between R-O material without clear yielding and materials with clear yielding plateau, referred to as non-R-O materials in this paper. Since most structural steels, in particular steels used for pipes, exhibit a clear yielding plateau there is a compelling need to incorporate the yielding characteristics into the R-O model fitting.

Figure 1. Schematic of R-O and non-R-O materials

On the other hand, the difficulties in use of RS method for cracked pipes have been well recognised (Cho et al. 2011, Kamaya and Machida 2010, Staat and Vu 2007, Kim et al. 2003). In RS method, an appropriate (optimized) reference stress for a cracked structure needs to be found first based on its limit load. This often requires detailed limit load analysis based on the 3D FEA or experimental work, as well as the trial-and-error process (Cho et al. 2011). However, for a pressurized pipe subject to a semi-elliptical surface crack, available limit loads published in literature are not consistent and the majority of limit load models are inaccurate (Kamaya and Machida 2010, Staat and Vu 2007, Kim et al. 2003). In comparison, the GE/EPRI method is more practical and easier to use. As the inaccurate estimation of elasto-plastic $J$-integral by the general GE/EPRI method is mainly caused by the use of $\mathrm{R}-\mathrm{O}$ mode, rather than by inherent deficiency of the method (Chattopadhyay 2006; Kim et al. 2001, 2002c), one feasible solution is to modify the original R-O model with parameter fitted from the test results to include both non-yielding materials (R-O materials) and materials with clear yielding plateau (non R-O 
materials). With this modification the GE/EPRI method can be applied to all materials regardless of their yielding behaviour.

101

This paper aims to develop a method for estimating the elasto-plastic $J$-integral of cracked pipes made of all types of steel. Solutions to elasto-plastic $J$-integrals are derived for external longitudinal semi-elliptical surface cracks (LSSC) in pressurised steel pipes. The GE/EPRI method is modified to include both R-O and non-R-O materials in determining the elasto-plastic $J$-integral of cracked pipes. A meshing technique is developed in the detailed three-dimensional finite element analysis (3D FEA) that incorporates the mixed types of quadratic tetrahedron and hexahedron elements. The developed method is also verified for both R-O and non-R-O materials. Effects of a wide range of pipe dimensions, crack geometries and material properties on the change of $J$-integrals along the crack front are thoroughly investigated.

The merit of the developed method is that it effectively extends the application of the general GE/PERI method to almost all types of steel which is the primarily construction material for all infrastructure. It also provides a useful tool for the failure assessment of pressurized steel pipes. The significance of this paper is that a 3D FEA and modified GE/EPRI method are combined to derive the solution to $J$-integral for external LSSC, which enables the consideration of a wide range of pipe dimensions, crack geometries and material properties.

\section{DEVELOPMENT OF THE METHOD}

As it is known an accurate $J$-integral for a pipe with LSSC can be obtained directly from 3D finite element analysis (FEA). However, it is often computation intensive and requires a high level of programming skills. Consequently, undertaking a detailed 3D FEA for any specific pipe and crack dimensions is unrealistic for practical engineering use. To overcome this, a practical method that can determine the $J$-integrals of cracked pipes by using a limited number of 
solutions predetermined from FEA is to be developed here.

According to the GE/EPRI method (Kumar et al. 1981), a simple expression for the elastoplastic $J$-integral for cracked structures made of R-O materials can be expressed as follows

$$
\begin{gathered}
J(a, P)=J^{e}\left(a_{e}, P\right)+J^{P}(a, P) \\
\text { with } J^{p}(a, P)=\alpha \varepsilon_{o} \sigma_{o} \operatorname{Lh}\left(g_{i}, n\right)\left(\frac{P}{P_{o}}\right)^{n+1}
\end{gathered}
$$

125

$$
\frac{\varepsilon}{\varepsilon_{o}}=\frac{\sigma}{\sigma_{o}}+\alpha\left(\frac{\sigma}{\sigma_{o}}\right)^{n}
$$

The above equations are theoretically valid only for Ramberg-Osgood materials, i.e., materials whose stress-strain relation follows the Ramberg-Osgood (R-O) model, which can be expressed as follows (Kumar et al. 1981)

where $\alpha$ and $n$ are material constants, $\sigma_{o}$ is normalising stress and $\varepsilon_{o}=\sigma_{o} / E$.

To extend the application of general GE/EPRI method, i.e., Equations (1) - (3) to non-R-O materials, instead of using Equation (4), a modified R-O model was proposed by 


$$
\begin{array}{ll}
\frac{\varepsilon}{\varepsilon_{o}}=\alpha^{\frac{1}{n+1}\left(\frac{\sigma}{\sigma_{o}}\right)^{n}} & \text { for } \frac{\sigma}{\sigma_{o}} \leq 1.0 \\
\varepsilon=\varepsilon_{1}+\frac{\varepsilon_{1,2}-\varepsilon_{1}}{0.2}\left(\frac{\sigma}{\sigma_{o}-1}\right) & \text { for } 1.0<\frac{\sigma}{\sigma_{o}}<1.2 \\
\frac{\varepsilon}{\varepsilon_{o}}=\alpha\left(\frac{\sigma}{\sigma_{o}}\right)^{n} & \text { for } \frac{\sigma}{\sigma_{o}} \geq 1.2
\end{array}
$$

138 where $\varepsilon_{1}$ is the strain obtained from the true stress-strain curve at yield strength $\sigma_{o}$, and $\varepsilon_{1,2}$ 139 is the strain determined at $\sigma=1.2 \sigma_{o}$. It can be seen that the parameters of original R-O model, 140 i.e., Equation (4), are modified in the form of Equation (5) with different parameters fitted from 141 test results. Equation (5) can be applied to both R-O materials and non-R-O materials.

142 Accordingly, Equation (2) can be reformulated as follows

$$
\begin{array}{ll}
J^{p}(a, P)=\alpha^{\frac{1}{n+1}} \varepsilon_{o} \sigma_{o} L h\left(g_{i}, n\right)\left(\frac{P}{P_{o}}\right)^{n+1} & \text { for } \frac{\sigma}{\sigma_{o}} \leq 1.0 \\
J^{p}(a, P)=J^{p 1}+\frac{J^{p 1,2}-J^{p 1}}{0.2}\left(\frac{P}{P_{o}}-1\right) & \text { for } 1.0<\frac{\sigma}{\sigma_{o}}<1.2 \\
J^{p}(a, P)=\alpha \varepsilon_{o} \sigma_{o} \operatorname{Lh}\left(g_{i}, n\right)\left(\frac{P}{P_{o}}\right)^{n+1} & \text { for } \frac{\sigma}{\sigma_{o}} \geq 1.2
\end{array}
$$

143 where $J^{p 1}$ is the plastic part of $J$-integral at $\sigma=\sigma_{o}$ and $J^{p 1,2}$ is the plastic part of $J$-integral 144 at $\sigma=1.2 \sigma_{o}$.

145 By applying Equation (6) to a pressurised pipe subject to external longitudinal semi-elliptical surface cracks (LSSC) as shown in Figure 2, the elasto-plastic $J$-integral can be determined 147 through superposing the elastic and fully plastic portions according to Equation (1) as follows

$$
\begin{array}{ll}
\hat{J}=J^{e}+\alpha^{\frac{1}{n+1}} \varepsilon_{o} \sigma_{o} L h\left(\frac{2 \theta}{\pi}, \frac{a}{c}, \frac{a}{d}, n, \frac{d}{R_{i}}\right)\left(\frac{P}{P_{o}}\right)^{n+1} & \text { for } \frac{\sigma}{\sigma_{o}} \leq 1.0 \\
\hat{J}=J^{e}+J^{p 1}+\frac{J^{p 1,2}-J^{p 1}}{0.2}\left(\frac{P}{P_{o}}-1\right) & \text { for } 1.0<\frac{\sigma}{\sigma_{o}}<1.2
\end{array}
$$




$$
\hat{J}=J^{e}+\alpha \varepsilon_{o} \sigma_{o} L h\left(\frac{2 \theta}{\pi}, \frac{a}{c}, \frac{a}{d}, n, \frac{d}{R_{i}}\right)\left(\frac{P}{P_{o}}\right)^{n+1} \text { for } \frac{\sigma}{\sigma_{o}} \geq 1.2 \text { or R-O materials }
$$

where $\hat{J}$ is the elasto-plastic $J$-integral, $\theta$ is the eccentric anomaly of the crack ellipse, $c$ is the half length of crack, $d$ is the pipe wall thickness, $R_{i}$ is the inner radius of pipe and $P_{o}=$ $d \sigma_{o} / R_{i}$. Equation (7) is the modified GE/EPRI method which can determine the elasto-plastic $J$-integral for both R-O and non-R-O steels.

Figure 2. Schematic for (a) a pipe with a semi-elliptical external surface crack; and (b) surface crack

\section{THREE-DIMENSIONAL FINITE ELEMENT ANALYSIS}

To apply the above method for predicting the elasto-plastic $J$-integral of a cracked pipe, the key is to derive a series of solutions to normalised fully plastic $J$-integrals for various geometrical and material properties. For external LSSC, the three-dimensional finite element method is apparently necessary to take into account the 3-D nature of the stress state in the vicinity of crack. Therefore, three-dimensional finite element models, based on Abaqus 6.14 software (Abaqus 2014), are developed in this study to evaluate the $J$-integrals.

\subsection{Development of FE Models}

In the developed FE models, a wide range of the relatively thick-wall pipes $\left(d / R_{\mathrm{i}}=0.1\right)$ to the thin-wall pipes $\left(d / R_{\mathrm{i}}=0.025\right)$ were considered to cover the dimensions of commonly used water, oil and gas pipes. For the geometries of the surface cracks, different aspect ratios $(a / c$ from 0.2 to 0.8 ) and depths (a/d from 0.2 to 0.8 ) were considered. Also, different strain hardening exponents ( $n$ from 3 to 10) were used in the Ramberg-Osgood material model based on deformation theory of plasticity. A total of 108 cases were considered with the variables 
summarized in Table 1. The length of the pipe under analysis was taken to be 20 times that of the corrosion pit length to reduce the boundary effects. Because of the symmetry, a quarter of the cylinder was modelled as illustrated in Figure 3. The pressure was directly applied to the inner surface of the pipe as a distributed surface load. The applied load increased proportionally and monotonically. The Poisson's ratio $v=0.3$, Young's modulus $E=207 \mathrm{GPa}$, yield stress $\sigma_{0}=$

$210 \mathrm{MPa}$ and material constant $\alpha=1$. It should be noted that the $h\left(\frac{2 \theta}{\pi}, \frac{a}{c}, \frac{a}{d}, n, \frac{d}{R_{i}}\right)$ as determined through Equation (3) is independent of the material parameters $\left(E, v, \sigma_{0}, \alpha\right)$ since it is normalized with respect to materials.

Figure 3. Finite element model of a thin-wall pipe with external semi-elliptical surface crack

The focused 15-node wedges elements (C3D15) (see Figure 3) were used at the crack front. The rest of the domain integral regions were meshed by 20-node hexahedron elements (C3D20R) with reduced integration points. Due to the complexity of the crack geometry, a meshing technique was developed such that the irregular region close to the crack region was meshed with quadratic tetrahedron elements. The tie constraints were applied to the interfaces between the irregular regions and domain integral regions.

The domain integral method was used to evaluate the total $J$-integral and the elastic $J$-integral. To consider the crack-tip strain singularity appropriately in the present elasto-plastic analysis, the crack-tip nodes were set free to displace (not tied) to include both $1 / r$ and $1 / \sqrt{r}$ singularity terms. But at the intersection of the free surface and the crack front, this crack-tip strain singularity does not exist in the power-law materials (Anderson 2017, Sih and Lee 1989). To reduce the effect of singularity change, a very fine mesh with 90-180 element segments was used at the front of cracks. This fine mesh can also ensure the accuracy of the $J$-integrals when 
the material becomes highly non-linear. Besides, since the $J$-integrals evaluated at the first block

of elements are normally inaccurate, the results from this first domain were neglected and the $J$-integrals from the outer four blocks were averaged to obtain the final result of $J$-integral. After the elastic $J$-integrals and the total $J$-integrals are obtained from FEA, the normalised fully plastic $J$-integrals $(h)$ can be determined through Equation (3).

The normalised fully plastic $J$-integral $h$ largely depends on applied loads if the load is small (Wang 2016). When the applied load increases, its dependence gradually decreases, eventually diminishing when the load becomes sufficiently large (Fu et al. 2017). Wang (2016) proposed a criterion for determining the fully plastic conditions of a cracked body; that is, the plastic $J$ integral component accounts for more than $95 \%$ of the total $J$-integral for all points along a crack front. This criterion was used in the present study.

\subsection{Verification of Finite Element Models}

Before conducting FEA for cracked pipes, it is essential to verify the accuracy of proposed FE models. For the SIFs determined based on LEFM and FE models, extensive verifications were previously conducted by Wang et al (2017) and Li and Yang (2012). Thus, in this paper, only the 3D FE method for determining the fully plastic $J$-integrals need to be verified. Two examples were used for verification.

The first one is an embedded penny-shaped crack in an infinite body (see Figures 4a). The length, width and height of the body with the embedded penny-shaped crack were taken to be 20 times that of the crack size (i.e., $H=20 a$ ) in the 3D FE model to reduce the boundary effect. The R-O material model was used with the strain hardening exponent of 3, 5 and 10 . The cracked body was subject to far-field tensile stresses that are perpendicular to the crack surface. To determine the normalised fully plastic $J$-integral $(h)$, Equation (4) was used with the inputs 
(elastic $J$-integral, total $J$-integral) directly calculated by FE model. Also, ' $P / P_{o}$ ' was replaced

216

217 with ' $\sigma_{\infty} / \sigma_{o}$ ' and the characteristic length $(L)$ was taken as the depth of crack $(a)$ in Equation (4).

In relation to the crack in the infinite body, an analytical solution, which was developed by $\mathrm{He}$ and Hutchinson (1981) based on a perturbation technique as follows

$$
h=\frac{6}{\pi}\left(1+\frac{3}{n}\right)^{-0.5}\left(\frac{\sigma_{1}}{\sigma_{\infty}}\right)^{2}
$$

where $\sigma_{\infty}$ is the effective stress, which equals $\sigma_{1}$ under the uniaxial tension loading and $\left|(1-\lambda) \sigma_{1}\right|$ under the triaxial tension loading, and $\lambda$ is the biaxiality ratio.

Figure 4. Schematic for (a) an embedded penny-shaped crack in an infinite body and a plate subject to semi-elliptical surface crack under far-field tensile stresses; and (b) one-quarter FE model of a cracked plate

Table 1 compares the normalised fully plastic $J$-integral $(h)$ obtained from Equation (4) to that from Equation (8). As it can be seen, a good agreement between the results of the proposed 3D FEA and that of the He and Hutchinson's solution was obtained. The maximum difference is only $2.34 \%$.

Table 2. Comparison of $h$ for a penny-shaped crack against the proposed FE method

The second one is a plate subject to semi-elliptical surface crack (see Figures $4 b$ ). For the semielliptical surface crack in a plate, both the shallow $(a / d=0.2)$ and deep $(a / d=0.8)$ cracks were considered. The R-O material model was also used with three different strain hardening exponents $(n=3,5$ and 10$)$. The loading and boundary conditions were set to be the same as the first example. The characteristic length $(L)$ was taken as the thickness of plate $(d)$ in Equation (4). The results determined by the proposed FE models are compared with those previously 
reported by Wang (2006). As Figures $5 \mathrm{a}$ and $5 \mathrm{~b}$ show, there is also a good agreement with the maximum difference less than $3.18 \%$ between them for both shallow and deep cracks. These two examples indicate the accuracy of the proposed FE models in evaluating the $J$-integrals.

Figure 5. Comparison of $h$ values from the present FE analyses and those of Wang (2006) with $n=3,5$ and 10 for: (a) $a / d=0.2$; (b) $a / d=0.8$

\section{VERIFICATION OF MODIFIED GE/EPRI METHOD}

After the FE models are verified, the normalised fully plastic $J$-integrals $(h)$ for external LSSC in pressurized pipes can be derived with various crack geometries, the pipe dimensions and strain hardening exponents. The normalised fully plastic $J$-integrals were determined at different locations along the crack front (i.e., at every 10 degrees; $\theta=10^{\circ}$ ). The characteristic length $L$ in Equation (4) was taken as the length of the crack $(2 c)$. As the singularity change at the surface point can cause the simulated $J$-integral at surface point inaccurate (Sih and Lee 1989), the $J$-integral values at surface points were estimated by extrapolation from those next to the surface. The derived normalised fully plastic $J$-integrals are tabulated as shown in Tables 3-6. From these tables, the elasto-plastic $J$-integrals of a pressurized pipe subjected to external crack can be estimated by the modified GE/PERI method with any other dimensions and material properties. However, before the practical engineering application, it is necessary to verify the accuracy of the modified GE/PERI method. To do this, two groups of 3D FE analyses were performed for verification purpose.

Table 3. Normalised fully plastic $J$-integral $h$ for cracked pipe with $a / c=0.2$

Table 4. Normalised fully plastic $J$-integral $h$ for cracked pipe with $a / c=0.4$

Table 5. Normalised fully plastic $J$-integral $h$ for cracked pipe with $a / c=0.6$

Table 6. Normalised fully plastic $J$-integral $h$ for cracked pipe with $a / c=0.8$ 
The first group of FE analyses was conducted to verify the accuracy of proposed method in predicting the elasto-plastic $J$-integral for cracked pipes made of the R-O materials. Three materials were assumed, denoted as 'Material A', 'Material B', 'Material C', which have the following properties: for Material A: $\alpha=1, n=4$; for Material B: $\alpha=3, n=4$; for

Material C: $\alpha=3, n=7$. The Young's modulus, Poisson's ratio and yield strength were assumed to be $207 \mathrm{GPa}, 0.3$ and $210 \mathrm{MPa}$, respectively. The geometries of crack and pipe were taken as $d / R_{\mathrm{i}}=0.05, a / c=0.6$ and $a / d=0.5$. The loads were applied up to 1.6 times of $P_{\mathrm{o}}$ to ensure the results covering a wide range, i.e., from elastic to fully plastic conditions. The elasto-plastic $J$-integral of cracked pipe under different loads were extracted from FE models directly. pipes with external LSSC was determined as follows (Fu et al. 2019)

$$
\begin{gathered}
J^{e}=\frac{\pi a\left(F \sigma^{\infty}\right)^{2}}{\bar{E} Q} \\
\text { with } \quad \begin{array}{c}
F=1+47\left(\frac{a}{c}\right)^{1.64} \\
\end{array} \\
\qquad \begin{array}{c}
h_{1}+h_{2}\left(\frac{a}{c}\right)+\left[h_{3}+h_{4}\left(\frac{a}{c}\right)+h_{5}\left(\frac{a}{c}\right)^{2}\right]\left(\frac{a}{d}\right)^{2}+ \\
\left.\left[h_{6}+h_{7}\left(\frac{a}{c}\right)+h_{8}\left(\frac{a}{c}\right)^{2}\right]\left(\frac{a}{d}\right)^{4}\right\} \exp \left(h_{9} \frac{d}{R_{i}}\right)
\end{array}
\end{gathered}
$$

where $\sigma^{\infty}$ is the remote stress, and $\sigma^{\infty}=p R_{i} / d$ for a cracked pipe under internal pressure, $\bar{E}=E$ for plane stress problem and $\bar{E}=E /\left(1-v^{2}\right)$ for plane strain problems, $F$ is the influence coefficients function, and the coefficients $h_{1}, h_{2}, \ldots, h_{9}$ are summarized in Table 7 .

Table 7. Coefficients in Equation (9) for the deepest point of semi-elliptical surface crack 
$J$-integrals for $n=4$ and $n=7$ from Table 5 , and then substituting the values of $\alpha, n$ and $P / P_{o}$ etc. into Equation (7c). The comparison between the results of 3D FE analysis and that predicted from the proposed method is shown in Figure 6. It can be seen from Figure 6 that the estimated results have an overall good agreement with FE results. The comparison of results indicates that the developed method has a sufficient accuracy in estimating the elasto-plastic $J$-integrals for R-O materials.

Figure 6. Comparison of the elasto-plastic $J$-integrals estimated by Equation (7c) with the FE results based on $\mathrm{R}-\mathrm{O}$ materials for $d / R_{\mathrm{i}}=0.05, a / c=0.6$ and $a / d=0.5$.

The second group of analyses were conducted to verify the accuracy of proposed method in predicting the elasto-plastic $J$-integral of cracked pipes made of non-R-O materials. Detailed 3D FE analyses were performed based on the incremental plasticity material model. The stressstrain curves of two realistic steel materials, namely, G250 and G350 were used as the inputs for material model. The Elastic modulus of G250 and G350 are $203 \mathrm{GPa}$ and $209 \mathrm{GPa}$, respectively. The Poisson's ratios of both materials were taken to be 0.3 . The geometries of crack and pipe in the 3D FE models were taken to be the same as that of the first group of analyses. The loads were also applied up to 1.6 times of $P_{\mathrm{o}}$ to ensure a fully plastic condition is reached.

The true stress-strain curves of G250 and G350 steels are presented in Figure 7. It can be seen from Figure 7 that there is yielding plateau in the stress-strain curves of G250 and G350 steels. To account for the characteristics of stress-strain curves, the Equation (5) was used with the fitted material parameters. For the purpose of comparison, the original R-O model (Equation 3) was also used. The fitted material parameters are presented in Table 8 . The fitted curves are also shown in Figures 7a and 7b, for G250 and G350, respectively. It can be clearly seen that there is a distinct deviation near the region of yielding plateau between the curve determined by 
Equation (3) and the stress-strain curve determined from the experiment. With use of the modified R-O model, i.e., Equation (5), this deviation was greatly reduced. Equation (7) was then used, based on the fitted material parameters, for predicting the elasto-plastic $J$-integrals of cracked pipe under different loads.

Table 8. R-O fitting results of G250 and G350 stress-strain curves (room temperature) Figure 7. R-O fittings by use of Equation (3) and Equation (5) for steels with yielding plateau for: (a) G250; (b) G350

The comparison between the results predicted by the modified GE/EPRI method and that from the detailed 3D FE analyses is shown in Figure 8. Also, the results predicted by the general GE/EPRI method are also presented. From the results, it can be clearly seen that the elastoplastic $J$-integrals of cracked pipes made of these two materials can be significantly underestimated with increasing the applied load if the original R-O fitting method was used. In comparison, this underestimation is greatly minimised by the modified GE/EPRI method, particularly after $P / P_{\mathrm{o}}>1.0$. This is mainly because that the fitted parameters of Equation (5) can characterise the stress-strain curve near the yielding plateau more accurately than Equation (3). It can be concluded that an overall good agreement between the results predicted by the modified GE/EPRI method and that from detailed 3D FE analyses has been obtained for both R-O materials and non R-O materials. This proves the effectiveness of the modified GE/EPRI method in predicting the elasto-plastic $J$-integral of cracked pipes made of different types of steel.

Figure 8. Comparison of elasto-plastic $J$-integrals determined by the developed method with the detailed FE results for $d / R_{\mathrm{i}}=0.05, a / c=0.6$ and $a / d=0.5$ : (a) G250; (b) G350 


\section{EFFECT OF AFFECTING FACTORS}

328

The changes of normalised fully plastic $J$-integrals along the whole crack front are presented in Figures 9 to 10 for different pipe dimensions, crack geometries, material properties. First, the results of normalised fully plastic $J$-integrals with different crack aspect ratios $(a / c=0.2,0.4,0.6$ and 0.8) and various crack depth-to-wall ratios $(a / d=0.2,0.5$ and 0.8$)$ are presented in Figure 9. It can be found from Figure 9a that the distributions of normalised fully plastic $J$-integral are similar under different crack aspect ratios for shallow cracks $(a / d=0.2)$. However, the general trends of normalised fully plastic $J$-integral are different for various crack aspect ratios when $a / d=0.5$ and 0.8 , as shown in Figure $9 \mathrm{~b}$ and $9 \mathrm{c}$. To be specific, the maximum values of normalised fully plastic $J$-integral are located at the deepest point of crack when $a / d=0.2$ while they are located between the surface point and the deepest point (approximately at $\theta=30^{\circ}$ ) when $a / d=0.5$ and 0.8 . This is because when the ligament in the remaining wall decreases (i.e., crack depth increases), the constraint of crack back-face reduces, leading to the decrease of $J$ integral at the deepest point of crack. This also implies that a shallow crack will propagate downwards and become deeper when the $J$-integral exceed its critical value. It can be concluded that both the direction of crack propagation and the locations of critical point are different for cracks with different geometries.

Figure 9. Change of normalised fully plastic $J$-integral values along the whole crack front in cracked pipe with $n=5, d / R=0.1$ and different $a / c$ for: (a) $a / d=0.2$; (b) $a / d=0.5$; (c) $a / d=0.8$

Second, the changes of normalised fully plastic $J$-integrals along the crack front are investigated under different pipe dimensions $(d / R)$ and strain hardening exponents $(n)$, as shown in Figure 10. It can be found that, in general, the pipe dimensions and strain hardening exponent do not significantly affect the trends of normalised fully plastic $J$-integrals. However, there is a difference of $7 \%$ to $12 \%$ in the normalised fully plastic $J$-integrals between the thick-wall pipes 
and thin-wall pipes. Similar results are also obtained from other geometric parameters of cracks and thus not repeated here. This result implies that the $J$-integral of thin-wall pipes can be overestimated if the solutions derived from thick-wall pipes are used. Therefore, the solutions to $J$-integral derived from the present study will be useful in accurately predicting the elastoplastic $J$-integrals for thin-wall pipes that are widely used in the current water or petroleum industries.

Figure 10. Change of normalised fully plastic $J$-integral values along the whole crack front in cracked pipe with different $d / R$ and $a / d$ for: (a) $n=3$; (b) $n=5$; (c) $n=10$

By comparing the Figures $10 \mathrm{a}, 10 \mathrm{~b}$ and $10 \mathrm{c}$, it can be seen that strain hardening exponent $(n)$ of material has a significant effect on the normalised fully plastic $J$-integral. Across Figure 9 to Figure 10, strain hardening exponent has the largest effect on the magnitude of normalised fully plastic $J$-integral. It is also found from Figure 10 c that, for a deep crack with a relatively large strain hardening exponent $(n=10)$, the normalised fully plastic $J$-integral slightly fluctuates along the crack front. The reason of this phenomenon was initially investigated in this study by comparing the results with different densities of meshing (45 to 450 element segments) along the crack front. The comparison of results shows that this phenomenon is independent of the meshing density. Instead, this is because a material with a large strain hardening approaches to be perfect plastic. As a result, the crack front and the remaining pipe-wall ligament become easier to be locally deformed. This finding can further help understanding the failure mechanisms of external LSSC in pressurised steel pipes.

\section{CONCLUSIONS}

In this paper a method to determine the elasto-plastic $J$-integral of cracked pipes made of all types of steel has been developed and verified. A meshing technique has been developed in the 
detailed three-dimensional finite element analysis (3D FEA) that incorporates the mixed types

of quadratic tetrahedron and hexahedron elements. Solutions to elasto-plastic $J$-integrals have been derived for external longitudinal semi-elliptical surface cracks (LSSC) in pressurised steel pipes. It has been found that the distributions of normalised fully plastic $J$-integral change with different crack depth to wall ratio $(a / d)$ and aspect ratios $(a / c)$ due to the change of the crack back-face constraint, and that the crack extension directions and the positions of critical points are different for shallow and deep surface cracks. It has also been found that there is a significant difference in the derived solutions to $J$-integral between the thick-wall pipes and thin-wall pipes, and that the strain hardening exponent has the largest influence on the normalised fully plastic $J$-integral. It can be concluded that the developed method can help pipe engineers and managers accurately predict the likelihood of elasto-plastic fractures in steel pipes.

\section{ACKNOWLEDGEMENT}

Financial support from the Australian Research Council under DP140101547, LP150100413 and DP170102211, and the National Natural Science Foundation of China with Grant No. 51820105014 is gratefully acknowledged.

\section{REFERENCE}

Abaqus, V. (2014). 6.14 Documentation. Dassault Systemes Simulia Corporation, 651.

Ainsworth, R. A. (1984). The assessment of defects in structures of strain hardening material. Engineering Fracture Mechanics, 19(4), 633-642.

Anderson, T. L. (2017). Fracture mechanics: fundamentals and applications. CRC press.

Anderson, R. B., \& Sullivan, T. L. (1966). Fracture mechanics of through-cracked cylindrical pressure vessels (No. NASA-TN-D-3252). National aeronautics and space administration cleveland oh lewis research center.

Al Laham, S., and Branch, S. I. (1998). Stress intensity factor and limit load handbook (Vol. 3). British Energy Generation Limited.

Arafah, D., Madia, M., Zerbst, U., Beretta, S., \& Cristea, M. E. (2015). Instability analysis of pressurised pipes with longitudinal surface cracks. International Journal of Pressure 
Bloom, J. T. (1983). A procedure for the assessment of the structural integrity of nuclear pressure vessels. Journal of Pressure Vessel Technology, 105(1), 28-34.

Cho, D. H., Seo, H. B., Kim, Y. J., Chang, Y. S., Jhung, M. J., and Choi, Y. H. (2011). Advances in J-integral estimation of circumferentially surface cracked pipes. Fatigue \& Fracture of Engineering Materials \& Structures, 34(9), 667-681.

Chattopadhyay, J. (2006). Improved J and COD estimation by GE/EPRI method in elastic to fully plastic transition zone. Engineering Fracture Mechanics, 73(14), 1959-1979.

EDF Energy (2015). "R6: Assessment of the integrity of structures containing defects", Revision 4, with amendments to Amendment 11, Gloucester.

Fu, G., Yang, W., and Li, C. Q. (2017). Elasto and fully plastic J-integrals for mixed mode fracture induced by inclined surface cracks in plates under biaxial loading. Engineering Fracture Mechanics, 186, 483-495.

Fu, G., Yang, W., Deng, W., Li, C. Q., and Setunge, S. (2019). Prediction of Fracture Failure of Steel Pipes With Sharp Corrosion Pits Using Time-Dependent Reliability Method With Lognormal Process. Journal of Pressure Vessel Technology, 141(3).

He, M. Y., and Hutchinson, J. W. (1981). The penny-shaped crack and the plane strain crack in an infinite body of power-law material. Journal of Applied Mechanics, 48(4), 830-840.

Jeong, J. U., Choi, J. B., Kim, M. K., Huh, N. S., and Kim, Y. J. (2016). Plastic influence functions for calculating $J$-integral of complex-cracks in pipe. International Journal of Pressure Vessels and Piping, 146, 11-21.

Kamaya, M., and Machida, H. (2010). Reference stress method for evaluation of failure assessment curve of cracked pipes in nuclear power plants. International Journal of Pressure Vessels and Piping, 87(1), 66-73.

Kiefner, J., Maxey, W., Eiber, R., and Duffy, A. (1973). Failure stress levels of flaws in pressurised cylinders. In Progress in flaw growth and fracture toughness testing. ASTM International.

Kim, Y. J., Huh, N. S., and Kim, Y. J. (2001). Enhanced reference stress-based J and crack opening displacement estimation method for leak-before-break analysis and comparison with GE. EPRI method. Fatigue \& Fracture of Engineering Materials \& Structures, 24(4), 243-254.

Kim, Y. J., Huh, N. S., and Kim, Y. J. (2002a). Quantification of pressure-induced hoop stress effect on fracture analysis of circumferential through-wall cracked pipes. Engineering Fracture Mechanics, 69(11), 1249-1267.

Kim, Y. J., Huh, N. S., Park, Y. J., \& Kim, Y. J. (2002b). Elastic-plastic J and COD estimates for axial through-wall cracked pipes. International journal of pressure vessels and piping, $79(6), 451-464$.

Kim, Y. J., Shim, D. J., Choi, J. B., and Kim, Y. J. (2002c). Approximate J estimates for tensionloaded plates with semi-elliptical surface cracks. Engineering fracture mechanics, 69(13), 1447-1463. 
Kim, Y. J., Shim, D. J., Huh, N. S., and Kim, Y. J. (2002d). Plastic limit pressures for cracked pipes using finite element limit analyses. International Journal of Pressure Vessels and Piping, 79(5), 321-330.

Kim, Y. J., Shim, D. J., Nikbin, K., Kim, Y. J., Hwang, S. S., and Kim, J. S. (2003). Finite element based plastic limit loads for cylinders with part-through surface cracks under combined loading. International Journal of Pressure Vessels and Piping, 80(7-8), 527-540.

Kim, Y. J., Kim, J. S., Park, Y. J., \& Kim, Y. J. (2004). Elastic-plastic fracture mechanics method for finite internal axial surface cracks in cylinders. Engineering Fracture Mechanics, 71(78), 925-944.

Koduru, S. D., and Nessim, M. A. (2017). Review of Quantita-tive Reliability Methods for Onshore Oil and Gas Pipe-lines. In Risk and Reliability Analysis: Theory and Applications (pp. 67-95). Springer, Cham.

Kumar, V. G. M. D., German, M. D., and Shih, C. F. (1981). Engineering approach for elastoplastic fracture analysis (No. EPRI-NP--1931). General Electric Co..

Kumar, V., German, M. D., Wilkening, W. W., Andrews, W. R., deLorenzi, H. G., and Mowbray, D. F. (1984). Advances in elastic-plastic fracture analysis. Final report (No. EPRI-NP3607). General Electric Co., Schenectady, NY (USA). Corporate Research and Development Center.

Laham, S. Al, and Branch, S. I. (1998). Stress intensity factor and limit load handbook (Vol. 3). British Energy Generation Limited.

Lei, Y. (2004). J-integral and limit load analysis of semi-elliptical surface cracks in plates under combined tension and bending. International journal of pressure vessels and piping, 81(1), 43-56.

Li, C. Q., and Yang, S. T. (2012). Stress intensity factors for high aspect ratio semi-elliptical internal surface cracks in pipes. International Journal of Pressure Vessels and Piping, 96, $13-23$.

Li, C. Q., Fu, G., and Yang, W. (2016). Stress intensity factors for inclined external surface cracks in pressurised pipes. Engineering Fracture Mechanics, 165, 72-86.

Liu, X., Lu, Z. X., Chen, Y., Sui, Y. L., and Dai, L. H. (2018). Failure Assessment for the HighStrength Pipelines with Constant-Depth Circumferential Surface Cracks. Advances in Materials Science and Engineering, 2018.

Makar, J. M., Desnoyers, R., and McDonald, S. E. (2001). Failure modes and mechanisms in grey cast iron pipe. In M. Knight \& N. Thomson (eds.), proceedings of the international conference on Underground Infrastructure Research (pp. 303-312). Boca Raton, FL: CRC Press.

Østby, E., Jayadevan, K. R., and Thaulow, C. (2005). Fracture response of pipelines subject to large plastic deformation under bending. International Journal of Pressure Vessels and Piping, 82(3), 201-215.

Park, J. G., Jeon, D. S., Huh, N. S., Lee, S. M., and Kim, Y. J. (2019, July). Simple Calculations of $J$-Integral for Through-Wall Crack in Welded Pipes Based on Failure Assessment Diagram. In Pressure Vessels and Piping Conference (Vol. 58974, p. V06AT06A064). American Society of Mechanical Engineers. 
Raju, I. S., and Newman Jr, J. C. (1982). Stress-Intensity Factor Influence Coefficients for Internal and External Surface Cracks in Cylindrical Vessels. Aspects of fracture mechanics in pressure vessels and piping, 37-49.

Scarth, D. A., Kim, Y. J., and Vanderglas, M. L. (1985). A critical review on the application of elasto-plastic fracture mechanics to nuclear pressure vessel and piping systems (No. OH-85-257-K). Ontario Hydro.

Sih, G. C., and Lee, Y. D. (1989). Review of triaxial crack border stress and energy behavior. Theoretical and Applied Fracture Mechanics, 12(1), 1-17.

Staat, M., and Vu, D. K. (2007). Limit analysis of flaws in pressurized pipes and cylindrical vessels. Part I: Axial defects. Engineering Fracture Mechanics, 74(3), 431-450.

Surh, H. B., Jang, Y. Y., Kim, S. C., Shim, D. J., and Huh, N. S. (2017). New J and COD estimates for thin-walled pipes with axial through-wall cracks and high strain hardening exponents. Theoretical and Applied Fracture Mechanics, 90, 75-84.

Standard, A. S. T. M. (2001). Standard test method for measurement of fracture toughness. ASTM, E1820-01, 1-46.

Yagawa, G., Kitajima, Y., and Ueda, H. (1993). Three-dimensional fully plastic solutions for semi-elliptical surface cracks. International journal of pressure vessels and piping, 53(3), 457-510.

Wang, W., Shi, W., and Li, C. Q. (2019). Time dependent reliability analysis for cast iron pipes subjected to pitting corrosion. International Journal of Pressure Vessels and Piping, 175, 103935.

Wang, W., Li, C. Q., and Shi, W. (2019). Degradation of mechanical property of corroded water pipes after long service. Urban Water Journal, 16(7), 494-504.

Wang, W., Zhou, A., Fu, G., Li, C. Q., Robert, D., and Mahmoodian, M. (2017). Evaluation of stress intensity factor for cast iron pipes with sharp corrosion pits. Engineering Failure Analysis, 81, 254-269.

Wang, X. (2006). Fully plastic J-integral solutions for surface cracked plates under biaxial loading. Engineering fracture mechanics, 73(11), 1581-1595.

Wang, X., and Lambert, S. B. (1996). Stress intensity factors and weight functions for longitudinal semi-elliptical surface cracks in thin pipes. International journal of pressure vessels and piping, 65(1), 75-87. 
1. Variables considered in the parametric FE analyses

2. Comparison of $h$ for a penny shaped crack against the proposed FE method

3. Normalised fully plastic $J$-integral $h$ for cracked pipe with $a / c=0.2$

521

4. Normalised fully plastic $J$-integral $h$ for cracked pipe with $a / c=0.4$

5. Normalised fully plastic $J$-integral $h$ for cracked pipe with $a / c=0.6$

523

6. Normalised fully plastic $J$-integral $h$ for cracked pipe with $a / c=0.8$

524

7. Coefficients in Equation (9) for the deepest point of semi-elliptical crack

525

8. R-O fitting results of G250 and G350 stress-strain curves (room temperature) 
Table 1 Variables considered in the parametric FE analyses

\begin{tabular}{cc}
\hline Variables & Value \\
\hline$a / c$ & $0.2,0.4,0.6,0.8$ \\
$a / d$ & $0.2,0.5,0.8$ \\
$n$ & $3,5,10$ \\
$d / R_{i}$ & $0.1,0.05,0.025$ \\
\hline
\end{tabular}

530 
Table 2 Comparison of $h$ for a penny shaped crack against the proposed FE method

\begin{tabular}{cccc}
\hline$n$ & Present FE results & He and Hutchinson (1981) & Difference (\%) \\
\hline 3 & 1.383 & 1.350 & 2.34 \\
5 & 1.537 & 1.510 & 1.75 \\
10 & 1.670 & 1.675 & -0.35 \\
\hline
\end{tabular}

534 
Table 3 Normalised fully plastic $J$-integral $h$ for cracked pipe with $a / c=0.2$

\begin{tabular}{|c|c|c|c|c|c|c|c|c|c|c|}
\hline & \multirow{2}{*}{$d / R_{i}$} & \multicolumn{3}{|c|}{$a / d=0.2$} & \multicolumn{3}{|c|}{$a / d=0.5$} & \multicolumn{3}{|c|}{$a / d=0.8$} \\
\hline$\theta$ & & $n=3$ & $n=5$ & $n=10$ & $n=3$ & $n=5$ & $n=10$ & $n=3$ & $n=5$ & $n=10$ \\
\hline 90 & \multirow{10}{*}{0.1} & 2.534 & 3.164 & 4.460 & 2.955 & 4.427 & 8.504 & 4.284 & 8.190 & 31.415 \\
\hline 80 & & 2.493 & 3.112 & 4.406 & 2.914 & 4.396 & 8.524 & 4.351 & 8.235 & 32.478 \\
\hline 70 & & 2.372 & 2.963 & 4.192 & 2.806 & 4.336 & 8.583 & 4.392 & 8.202 & 32.152 \\
\hline 60 & & 2.183 & 2.735 & 3.853 & 2.542 & 3.975 & 8.038 & 4.469 & 8.304 & 30.022 \\
\hline 50 & & 1.933 & 2.427 & 3.424 & 2.212 & 3.550 & 7.486 & 4.294 & 8.143 & 29.256 \\
\hline 40 & & 1.636 & 2.064 & 2.946 & 1.826 & 3.018 & 6.671 & 3.847 & 7.635 & 28.499 \\
\hline 30 & & 1.302 & 1.649 & 2.338 & 1.409 & 2.368 & 5.405 & 3.114 & 6.557 & 26.119 \\
\hline 20 & & 0.952 & 1.211 & 1.729 & 1.007 & 1.719 & 4.047 & 2.231 & 4.948 & 20.812 \\
\hline 10 & & 0.628 & 0.799 & 1.137 & 0.654 & 1.133 & 2.765 & 1.401 & 3.219 & 14.479 \\
\hline 0 & & 0.234 & 0.256 & 0.298 & 0.199 & 0.275 & 0.490 & 0.322 & 0.549 & 1.903 \\
\hline 90 & \multirow{10}{*}{0.05} & 2.363 & 2.877 & 4.052 & 2.672 & 4.075 & 7.733 & 3.874 & 7.466 & 28.340 \\
\hline 80 & & 2.296 & 2.809 & 3.972 & 2.698 & 4.031 & 7.715 & 3.928 & 7.441 & 29.314 \\
\hline 70 & & 2.232 & 2.702 & 3.838 & 2.584 & 3.927 & 7.790 & 3.970 & 7.412 & 28.938 \\
\hline 60 & & 1.975 & 2.536 & 3.543 & 2.335 & 3.664 & 7.244 & 4.052 & 7.559 & 27.057 \\
\hline 50 & & 1.742 & 2.205 & 3.086 & 1.998 & 3.224 & 6.751 & 3.928 & 7.326 & 26.397 \\
\hline 40 & & 1.558 & 1.943 & 2.704 & 1.679 & 2.763 & 6.085 & 3.500 & 6.913 & 25.670 \\
\hline 30 & & 1.170 & 1.578 & 2.114 & 1.314 & 2.169 & 4.890 & 2.832 & 5.917 & 23.535 \\
\hline 20 & & 0.912 & 1.171 & 1.577 & 0.983 & 1.548 & 3.707 & 2.098 & 4.480 & 18.790 \\
\hline 10 & & 0.651 & 0.781 & 1.060 & 0.607 & 1.050 & 2.533 & 1.305 & 2.924 & 13.104 \\
\hline 0 & & 0.295 & 0.240 & 0.364 & 0.200 & 0.322 & 0.500 & 0.292 & 0.567 & 1.723 \\
\hline 90 & \multirow{10}{*}{0.025} & 2.284 & 2.709 & 3.806 & 2.502 & 3.878 & 7.276 & 3.624 & 7.039 & 26.418 \\
\hline 80 & & 2.190 & 2.622 & 3.696 & 2.589 & 3.821 & 7.222 & 3.666 & 6.953 & 27.344 \\
\hline 70 & & 2.174 & 2.552 & 3.636 & 2.459 & 3.673 & 7.313 & 3.710 & 6.926 & 26.914 \\
\hline 60 & & 1.851 & 2.438 & 3.372 & 2.221 & 3.498 & 6.744 & 3.798 & 7.119 & 25.202 \\
\hline 50 & & 1.624 & 2.069 & 2.878 & 1.867 & 3.028 & 6.288 & 3.720 & 6.813 & 24.612 \\
\hline 40 & & 1.530 & 1.896 & 2.565 & 1.593 & 2.614 & 5.742 & 3.290 & 6.467 & 23.894 \\
\hline 30 & & 1.089 & 1.561 & 1.974 & 1.267 & 2.053 & 4.569 & 2.667 & 5.516 & 21.914 \\
\hline 20 & & 0.905 & 1.172 & 1.487 & 0.988 & 1.440 & 3.510 & 2.043 & 4.191 & 17.535 \\
\hline 10 & & 0.690 & 0.787 & 1.019 & 0.587 & 1.010 & 2.404 & 1.259 & 2.746 & 12.258 \\
\hline 0 & & 0.363 & 0.229 & 0.433 & 0.206 & 0.369 & 0.525 & 0.276 & 0.599 & 1.616 \\
\hline
\end{tabular}


Table 4 Normalised fully plastic $J$-integral $h$ for cracked pipe with $a / c=0.4$

\begin{tabular}{|c|c|c|c|c|c|c|c|c|c|c|}
\hline & \multirow{2}{*}{$d / R_{i}$} & \multicolumn{3}{|c|}{$a / d=0.2$} & \multicolumn{3}{|c|}{$a / d=0.5$} & \multicolumn{3}{|c|}{$a / d=0.8$} \\
\hline$\theta$ & & $n=3$ & $n=5$ & $n=10$ & $n=3$ & $n=5$ & $n=10$ & $n=3$ & $n=5$ & $n=10$ \\
\hline 90 & \multirow{10}{*}{0.1} & 3.758 & 4.534 & 6.037 & 2.828 & 3.880 & 6.518 & 2.679 & 4.126 & 9.356 \\
\hline 80 & & 3.703 & 4.500 & 5.997 & 2.814 & 3.860 & 6.451 & 2.704 & 4.133 & 9.210 \\
\hline 70 & & 3.574 & 4.347 & 5.799 & 2.769 & 3.832 & 6.455 & 2.799 & 4.231 & 9.384 \\
\hline 60 & & 3.352 & 4.100 & 5.420 & 2.679 & 3.762 & 6.469 & 2.926 & 4.355 & 9.226 \\
\hline 50 & & 3.068 & 3.778 & 5.015 & 2.525 & 3.609 & 6.314 & 3.063 & 4.655 & 9.849 \\
\hline 40 & & 2.719 & 3.371 & 4.481 & 2.304 & 3.354 & 6.018 & 3.086 & 4.852 & 10.552 \\
\hline 30 & & 2.332 & 2.908 & 3.886 & 2.021 & 2.981 & 5.426 & 2.922 & 4.733 & 10.683 \\
\hline 20 & & 1.932 & 2.427 & 3.231 & 1.707 & 2.531 & 4.670 & 2.605 & 4.276 & 9.816 \\
\hline 10 & & 1.556 & 1.940 & 2.527 & 1.386 & 2.007 & 3.624 & 2.149 & 3.459 & 7.861 \\
\hline 0 & & 0.585 & 1.273 & 1.545 & 0.463 & 0.568 & 0.836 & 0.939 & 1.260 & 2.343 \\
\hline 90 & \multirow{10}{*}{0.05} & 3.406 & 4.125 & 5.533 & 2.573 & 3.554 & 5.937 & 2.463 & 3.787 & 8.479 \\
\hline 80 & & 3.399 & 4.136 & 5.494 & 2.563 & 3.498 & 5.817 & 2.508 & 3.762 & 8.295 \\
\hline 70 & & 3.228 & 4.014 & 5.308 & 2.503 & 3.533 & 5.888 & 2.540 & 3.830 & 8.523 \\
\hline 60 & & 3.030 & 3.785 & 4.903 & 2.415 & 3.467 & 5.915 & 2.719 & 3.968 & 8.406 \\
\hline 50 & & 2.807 & 3.476 & 4.599 & 2.352 & 3.306 & 5.704 & 2.848 & 4.200 & 8.931 \\
\hline 40 & & 2.500 & 3.044 & 4.087 & 2.152 & 3.106 & 5.505 & 2.785 & 4.386 & 9.583 \\
\hline 30 & & 2.178 & 2.673 & 3.597 & 1.862 & 2.744 & 4.938 & 2.716 & 4.276 & 9.689 \\
\hline 20 & & 1.787 & 2.203 & 2.936 & 1.589 & 2.335 & 4.264 & 2.374 & 3.855 & 8.859 \\
\hline 10 & & 1.465 & 1.747 & 2.279 & 1.340 & 1.887 & 3.289 & 1.956 & 3.180 & 7.131 \\
\hline 0 & & 0.538 & 1.227 & 1.402 & 0.442 & 0.562 & 0.804 & 0.905 & 1.217 & 2.133 \\
\hline 90 & \multirow{10}{*}{0.025} & 3.190 & 3.884 & 5.244 & 2.419 & 3.368 & 5.591 & 2.341 & 3.592 & 7.940 \\
\hline 80 & & 3.230 & 3.932 & 5.203 & 2.418 & 3.277 & 5.421 & 2.411 & 3.544 & 7.721 \\
\hline 70 & & 3.017 & 3.832 & 5.025 & 2.337 & 3.371 & 5.549 & 2.381 & 3.584 & 8.007 \\
\hline 60 & & 2.832 & 3.615 & 4.585 & 2.248 & 3.307 & 5.593 & 2.611 & 3.744 & 7.916 \\
\hline 50 & & 2.655 & 3.307 & 4.357 & 2.271 & 3.132 & 5.330 & 2.742 & 3.921 & 8.372 \\
\hline 40 & & 2.376 & 2.842 & 3.857 & 2.083 & 2.980 & 5.207 & 2.594 & 4.099 & 9.001 \\
\hline 30 & & 2.106 & 2.539 & 3.441 & 1.775 & 2.613 & 4.644 & 2.614 & 3.996 & 9.088 \\
\hline 20 & & 1.711 & 2.065 & 2.759 & 1.527 & 2.230 & 4.026 & 2.241 & 3.588 & 8.259 \\
\hline 10 & & 1.423 & 1.626 & 2.122 & 1.335 & 1.832 & 3.089 & 1.840 & 3.024 & 6.688 \\
\hline 0 & & 0.517 & 1.225 & 1.320 & 0.439 & 0.572 & 0.795 & 0.901 & 1.215 & 2.011 \\
\hline
\end{tabular}


Table 5 Normalised fully plastic $J$-integral $h$ for cracked pipe with $a / c=0.6$

\begin{tabular}{|c|c|c|c|c|c|c|c|c|c|c|}
\hline \multirow{2}{*}{$\theta$} & \multirow{2}{*}{$d / R_{i}$} & \multicolumn{3}{|c|}{$a / d=0.2$} & \multicolumn{3}{|c|}{$a / d=0.5$} & \multicolumn{3}{|c|}{$a / d=0.8$} \\
\hline & & $n=3$ & $n=5$ & $n=10$ & $n=3$ & $n=5$ & $n=10$ & $n=3$ & $n=5$ & $n=10$ \\
\hline 90 & \multirow{10}{*}{0.1} & 4.388 & 5.305 & 7.071 & 2.613 & 3.469 & 5.539 & 2.116 & 3.154 & 6.548 \\
\hline 80 & & 4.350 & 5.234 & 6.879 & 2.609 & 3.466 & 5.577 & 2.163 & 3.200 & 6.511 \\
\hline 70 & & 4.245 & 5.115 & 6.700 & 2.609 & 3.506 & 5.712 & 2.233 & 3.276 & 6.626 \\
\hline 60 & & 4.075 & 4.924 & 6.463 & 2.588 & 3.524 & 5.820 & 2.349 & 3.340 & 6.362 \\
\hline 50 & & 3.850 & 4.666 & 6.147 & 2.534 & 3.489 & 5.786 & 2.511 & 3.565 & 6.663 \\
\hline 40 & & 3.583 & 4.353 & 5.755 & 2.436 & 3.383 & 5.690 & 2.651 & 3.886 & 7.489 \\
\hline 30 & & 3.280 & 3.971 & 5.238 & 2.299 & 3.203 & 5.347 & 2.689 & 3.993 & 7.873 \\
\hline 20 & & 2.971 & 3.559 & 4.647 & 2.128 & 2.944 & 4.942 & 2.635 & 3.951 & 7.868 \\
\hline 10 & & 2.627 & 3.053 & 3.883 & 1.898 & 2.523 & 4.044 & 2.460 & 3.607 & 6.952 \\
\hline 0 & & 1.303 & 1.393 & 1.561 & 0.762 & 0.897 & 1.223 & 0.903 & 1.090 & 1.670 \\
\hline 90 & \multirow{10}{*}{0.05} & 4.010 & 4.779 & 6.385 & 2.437 & 3.188 & 5.075 & 1.910 & 2.881 & 5.990 \\
\hline 80 & & 4.015 & 4.805 & 6.226 & 2.355 & 3.155 & 5.052 & 1.946 & 2.908 & 5.937 \\
\hline 70 & & 3.841 & 4.612 & 6.068 & 2.362 & 3.199 & 5.149 & 2.063 & 2.992 & 6.003 \\
\hline 60 & & 3.677 & 4.428 & 5.897 & 2.359 & 3.181 & 5.251 & 2.156 & 3.057 & 5.801 \\
\hline 50 & & 3.469 & 4.243 & 5.545 & 2.367 & 3.185 & 5.214 & 2.323 & 3.221 & 6.031 \\
\hline 40 & & 3.258 & 3.939 & 5.272 & 2.286 & 3.070 & 5.167 & 2.413 & 3.559 & 6.779 \\
\hline 30 & & 2.988 & 3.638 & 4.760 & 2.101 & 2.935 & 4.900 & 2.433 & 3.606 & 7.135 \\
\hline 20 & & 2.735 & 3.226 & 4.206 & 1.977 & 2.674 & 4.495 & 2.400 & 3.566 & 7.132 \\
\hline 10 & & 2.438 & 2.839 & 3.546 & 1.736 & 2.294 & 3.680 & 2.312 & 3.255 & 6.297 \\
\hline 0 & & 1.179 & 1.307 & 1.492 & 0.728 & 0.844 & 1.169 & 0.833 & 0.987 & 1.504 \\
\hline 90 & \multirow{10}{*}{0.025} & 3.788 & 4.445 & 5.961 & 2.355 & 3.031 & 4.808 & 1.778 & 2.725 & 5.666 \\
\hline 80 & & 3.833 & 4.567 & 5.824 & 2.197 & 2.966 & 4.728 & 1.812 & 2.733 & 5.600 \\
\hline 70 & & 3.597 & 4.292 & 5.681 & 2.210 & 3.014 & 4.798 & 1.974 & 2.823 & 5.618 \\
\hline 60 & & 3.433 & 4.118 & 5.567 & 2.222 & 2.971 & 4.896 & 2.046 & 2.894 & 5.473 \\
\hline 50 & & 3.230 & 3.985 & 5.168 & 2.292 & 3.005 & 4.853 & 2.225 & 3.003 & 5.646 \\
\hline 40 & & 3.066 & 3.687 & 5.001 & 2.216 & 2.883 & 4.850 & 2.273 & 3.367 & 6.343 \\
\hline 30 & & 2.815 & 3.448 & 4.470 & 1.985 & 2.785 & 4.643 & 2.275 & 3.369 & 6.687 \\
\hline 20 & & 2.605 & 3.021 & 3.933 & 1.899 & 2.516 & 4.229 & 2.256 & 3.328 & 6.682 \\
\hline 10 & & 2.338 & 2.734 & 3.353 & 1.640 & 2.160 & 3.467 & 2.249 & 3.033 & 5.899 \\
\hline 0 & & 1.106 & 1.272 & 1.475 & 0.721 & 0.819 & 1.157 & 0.797 & 0.923 & 1.401 \\
\hline
\end{tabular}


Table 6 Normalised fully plastic $J$-integral $h$ for cracked pipe with $a / c=0.8$

\begin{tabular}{|c|c|c|c|c|c|c|c|c|c|c|}
\hline & \multirow{2}{*}{$d / R_{i}$} & \multicolumn{3}{|c|}{$a / d=0.2$} & \multicolumn{3}{|c|}{$a / d=0.5$} & \multicolumn{3}{|c|}{$a / d=0.8$} \\
\hline$\theta$ & & $n=3$ & $n=5$ & $n=10$ & $n=3$ & $n=5$ & $n=10$ & $n=3$ & $n=5$ & $n=10$ \\
\hline 90 & \multirow{10}{*}{0.1} & 4.605 & 5.594 & 7.394 & 2.420 & 3.129 & 4.706 & 1.862 & 2.774 & 5.555 \\
\hline 80 & & 4.587 & 5.555 & 7.294 & 2.427 & 3.143 & 4.708 & 1.876 & 2.717 & 5.286 \\
\hline 70 & & 4.542 & 5.506 & 7.229 & 2.456 & 3.211 & 4.853 & 1.945 & 2.759 & 5.214 \\
\hline 60 & & 4.468 & 5.418 & 7.114 & 2.490 & 3.302 & 5.134 & 2.078 & 2.912 & 5.330 \\
\hline 50 & & 4.369 & 5.301 & 6.974 & 2.513 & 3.368 & 5.297 & 2.263 & 3.217 & 5.918 \\
\hline 40 & & 4.777 & 5.134 & 6.726 & 2.519 & 3.393 & 5.362 & 2.435 & 3.553 & 6.725 \\
\hline 30 & & 4.104 & 4.909 & 6.317 & 2.499 & 3.354 & 5.293 & 2.554 & 3.737 & 7.200 \\
\hline 20 & & 3.933 & 4.606 & 5.640 & 2.440 & 3.208 & 4.920 & 2.600 & 3.770 & 7.135 \\
\hline 10 & & 3.670 & 4.136 & 4.624 & 2.296 & 2.880 & 4.158 & 2.538 & 3.569 & 6.458 \\
\hline 0 & & 1.625 & 1.832 & 2.132 & 0.943 & 1.077 & 1.372 & 1.044 & 2.449 & 3.883 \\
\hline 90 & \multirow{10}{*}{0.05} & 4.165 & 5.111 & 6.655 & 2.187 & 2.881 & 4.290 & 1.676 & 2.503 & 5.092 \\
\hline 80 & & 4.133 & 5.034 & 6.620 & 2.245 & 2.836 & 4.305 & 1.746 & 2.542 & 4.842 \\
\hline 70 & & 4.145 & 5.006 & 6.574 & 2.285 & 2.982 & 4.389 & 1.834 & 2.485 & 4.740 \\
\hline 60 & & 4.051 & 4.919 & 6.430 & 2.320 & 3.062 & 4.653 & 1.946 & 2.706 & 4.848 \\
\hline 50 & & 3.959 & 4.865 & 6.276 & 2.294 & 3.074 & 4.859 & 2.114 & 2.899 & 5.371 \\
\hline 40 & & 4.385 & 4.716 & 6.091 & 2.307 & 3.141 & 4.832 & 2.236 & 3.249 & 6.080 \\
\hline 30 & & 3.731 & 4.481 & 5.696 & 2.277 & 3.112 & 4.839 & 2.373 & 3.371 & 6.481 \\
\hline 20 & & 3.543 & 4.240 & 5.080 & 2.277 & 2.985 & 4.455 & 2.358 & 3.419 & 6.434 \\
\hline 10 & & 3.347 & 3.764 & 4.202 & 2.142 & 2.625 & 3.824 & 2.373 & 3.242 & 5.895 \\
\hline 0 & & 1.481 & 1.712 & 1.949 & 0.859 & 1.052 & 1.316 & 0.956 & 2.297 & 3.569 \\
\hline 90 & \multirow{10}{*}{0.025} & 3.899 & 4.834 & 6.193 & 2.043 & 2.744 & 4.042 & 1.560 & 2.337 & 4.824 \\
\hline 80 & & 3.845 & 4.711 & 6.215 & 2.145 & 2.647 & 4.069 & 1.679 & 2.457 & 4.584 \\
\hline 70 & & 3.913 & 4.703 & 6.181 & 2.196 & 2.866 & 4.106 & 1.794 & 2.312 & 4.460 \\
\hline 60 & & 3.795 & 4.615 & 6.010 & 2.237 & 2.940 & 4.364 & 1.883 & 2.603 & 4.559 \\
\hline 50 & & 3.707 & 4.620 & 5.840 & 2.169 & 2.901 & 4.607 & 2.046 & 2.698 & 5.038 \\
\hline 40 & & 4.161 & 4.484 & 5.699 & 2.184 & 3.012 & 4.501 & 2.128 & 3.076 & 5.687 \\
\hline 30 & & 3.511 & 4.229 & 5.306 & 2.144 & 2.991 & 4.579 & 2.285 & 3.141 & 6.029 \\
\hline 20 & & 3.302 & 4.035 & 4.728 & 2.199 & 2.873 & 4.169 & 2.212 & 3.206 & 6.001 \\
\hline 10 & & 3.156 & 3.538 & 3.951 & 2.064 & 2.474 & 3.637 & 2.294 & 3.043 & 5.562 \\
\hline 0 & & 1.391 & 1.657 & 1.844 & 0.811 & 1.058 & 1.307 & 0.909 & 2.227 & 3.397 \\
\hline
\end{tabular}


Table 7 Coefficients in Equation (9) for the deepest point of crack

\begin{tabular}{lllllllll}
\hline$h_{1}$ & $h_{2}$ & $h_{3}$ & $h_{4}$ & $h_{5}$ & $h_{6}$ & $h_{7}$ & $h_{8}$ & $h_{9}$ \\
\hline 0.513 & 0.592 & -0.204 & 3.966 & -2.485 & 2.022 & -6.519 & 3.552 & -0.437 \\
\hline
\end{tabular}

554 
557 Table 8 R-O fitting results of G250 and G350 stress-strain curves (room temperature)

\begin{tabular}{lcccc}
\hline & \multicolumn{2}{c}{ G250 } & \multicolumn{2}{c}{ G350 } \\
\cline { 2 - 5 } & $\alpha$ & $n$ & $\alpha$ & $n$ \\
\hline Equaiton (3) & 5.365 & 5.096 & 7.757 & 6.387 \\
Equation (5) & 5.450 & 4.596 & 7.193 & 6.112 \\
\hline
\end{tabular}

558 


\section{LIST OF FIGURES}

1. Schematic of R-O and non-R-O materials

2. Schematic for (a) a pipe with a semi-elliptical external surface crack; and (b) surface crack

3. Finite element model of a thin-wall pipe with external semi-elliptical surface crack

4. Schematic for (a) an embedded penny-shaped crack in an infinite body and a plate subject to semi-elliptical surface crack under far-field tensile stresses; and (b) one-quarter FE model of a cracked plate

5. Comparison of $h$ values from the present FE analyses and those of Wang (2006) with $n=3$, 5 and 10 for: (a) $a / d=0.2$; (b) $a / d=0.8$

6. Comparison of the elasto-plastic $J$-integrals estimated by Equation (7c) with the FE results based on R-O materials for $d / R_{\mathrm{i}}=0.05, a / c=0.6$ and $a / d=0.5$

7. R-O fittings by use of Equation (3) and Equation (5) for steels with yielding plateau for: (a) G250; (b) G350

8. Comparison of elasto-plastic $J$-integrals determined by the developed method with the detailed FE results for $d / R_{\mathrm{i}}=0.05, a / c=0.6$ and $a / d=0.5$ : (a) G250; (b) G350

9. Change of normalised fully plastic $J$-integral values along the whole crack front in cracked pipe with $n=5, d / R=0.1$ and different $a / c$ for: (a) $a / d=0.2$; (b) $a / d=0.5$; (c) $a / d=0.8$

10. Change of normalised fully plastic $J$-integral values along the whole crack front in cracked pipe with different $d / R$ and $a / d$ for: (a) $n=3$; (b) $n=5$; (c) $n=10$ 


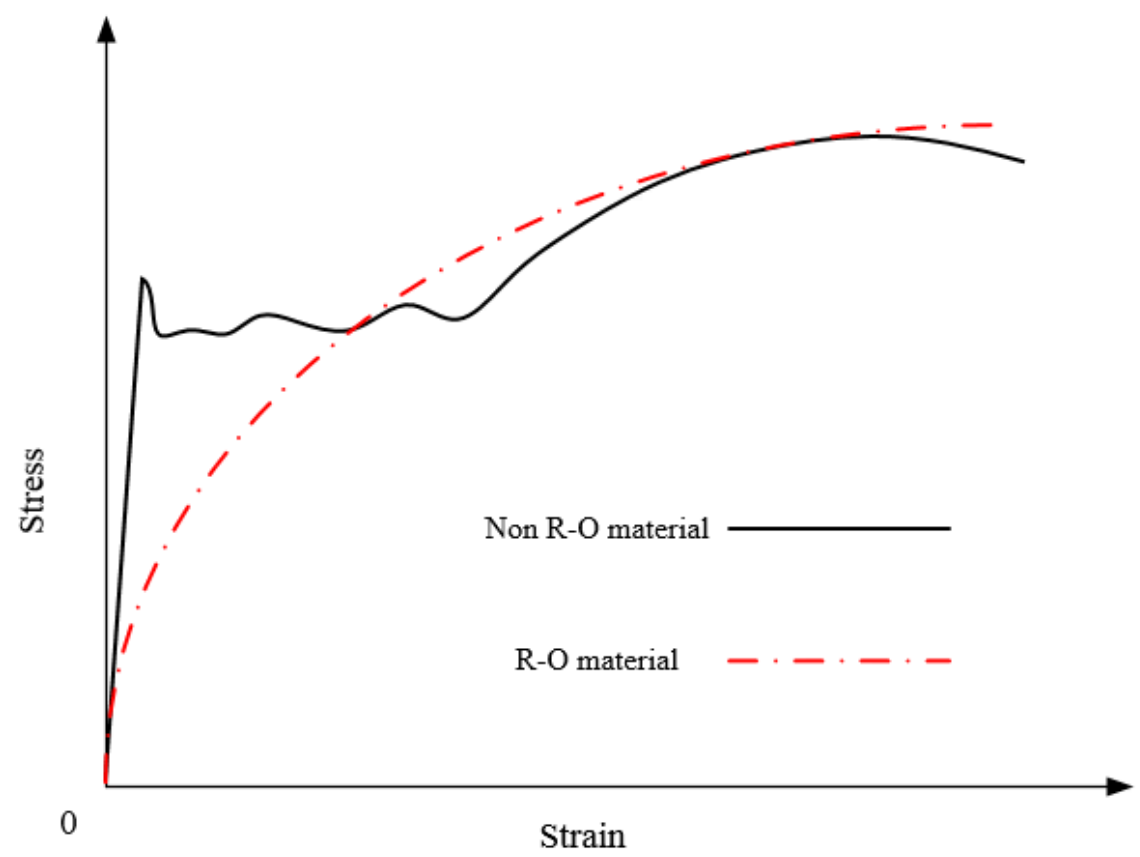

Figure 1 Schematic of R-O and non-R-O materials 


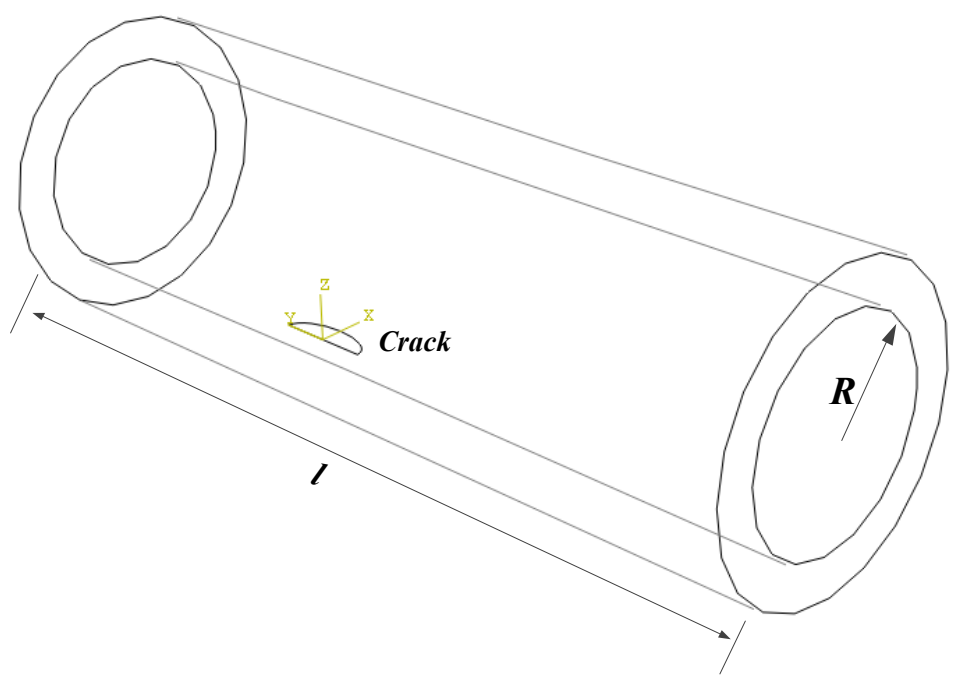

(a)

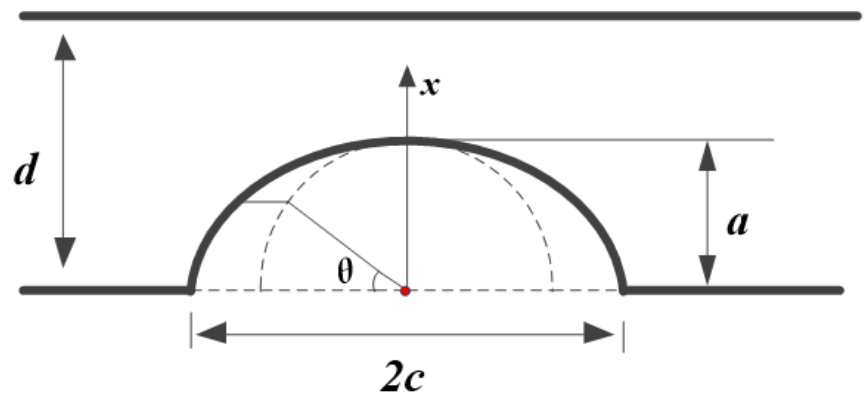

(b)

Figure 2 Schematic for (a) a pipe with a semi-elliptical external surface crack; and (b) 


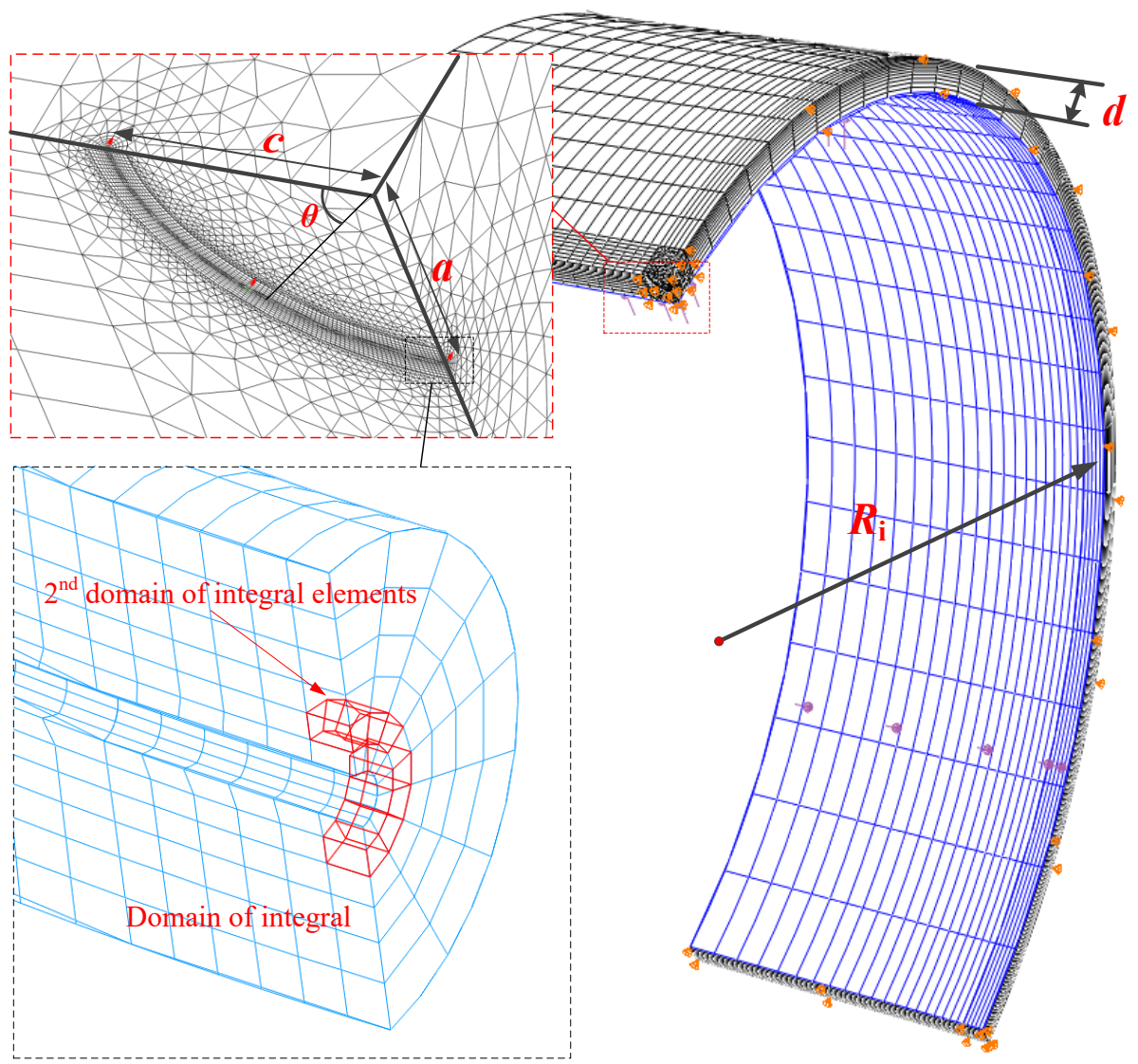

Figure 3 Finite element model of a thin-wall pipe with external semi-elliptical surface crack 

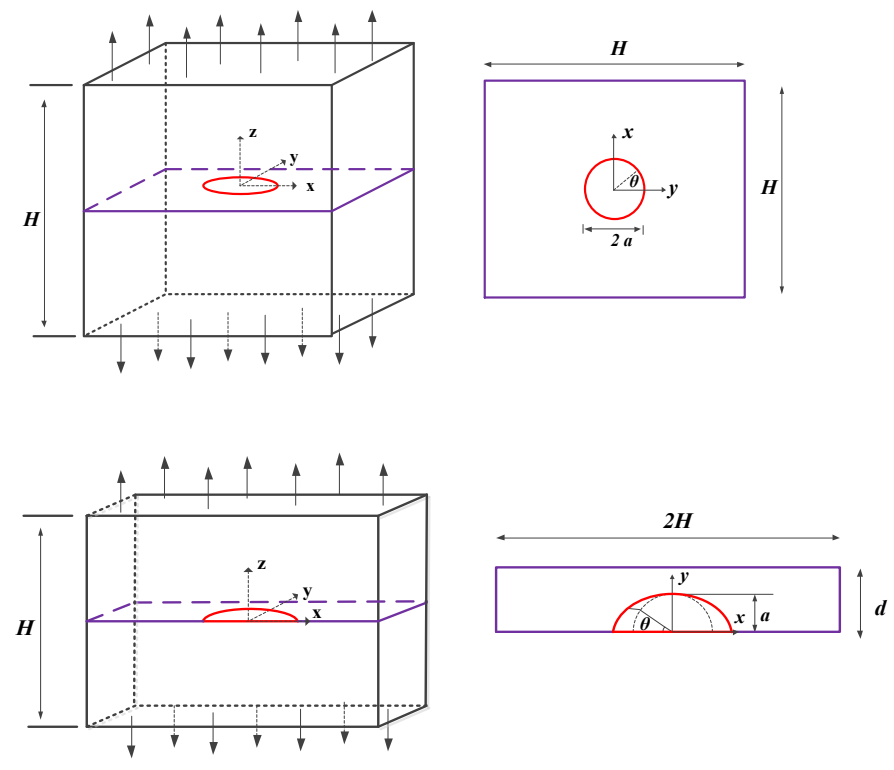

(a)

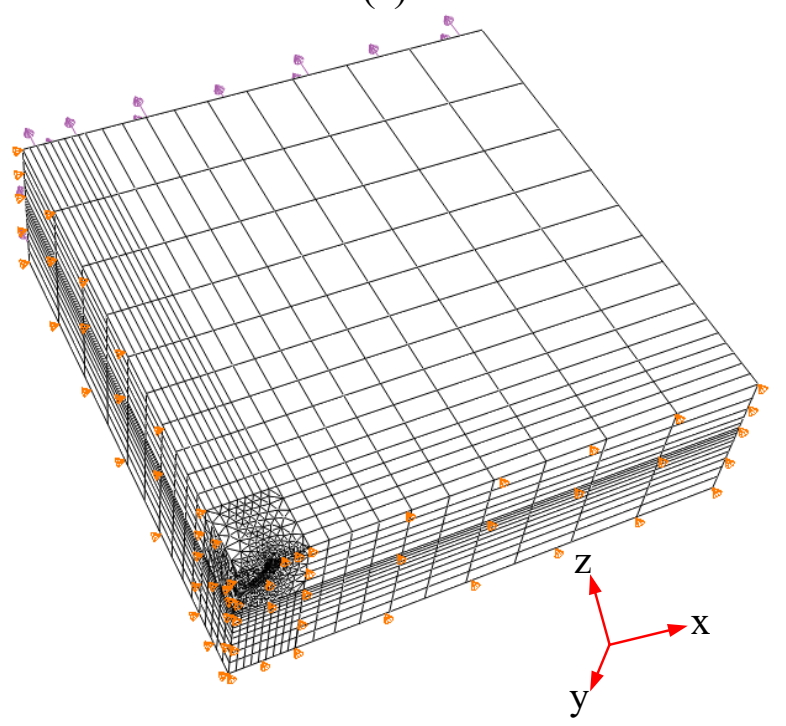

(b)

598 Figure 4 Schematic for (a) an embedded penny-shaped crack in an infinite body and a 599 plate subject to semi-elliptical surface crack under far-field tensile stresses; and (b) one600 quarter FE model of a cracked plate

601 


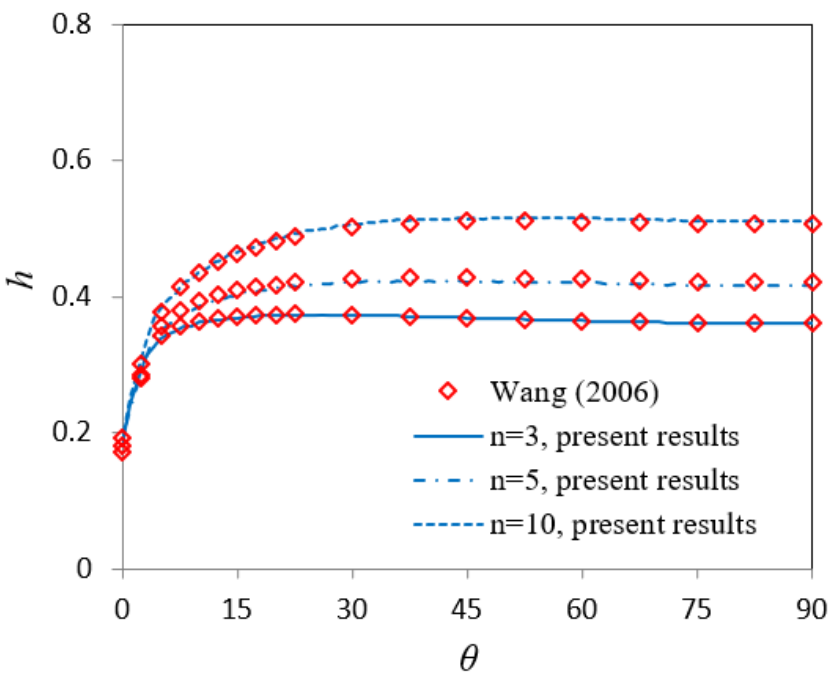

(a)

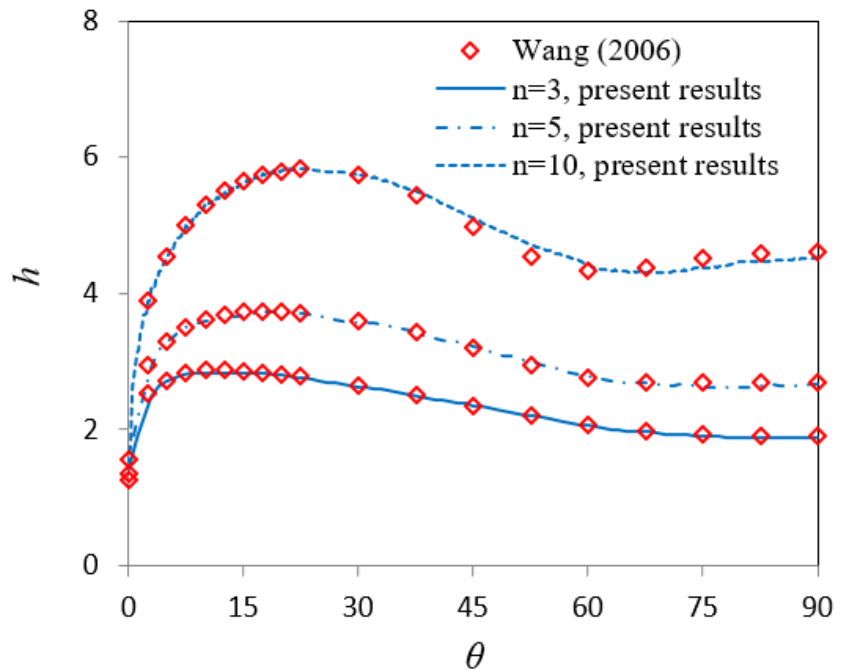

(b)

Figure 5 Comparison of $h$ values from the present FE analyses and those of Wang (2006) 


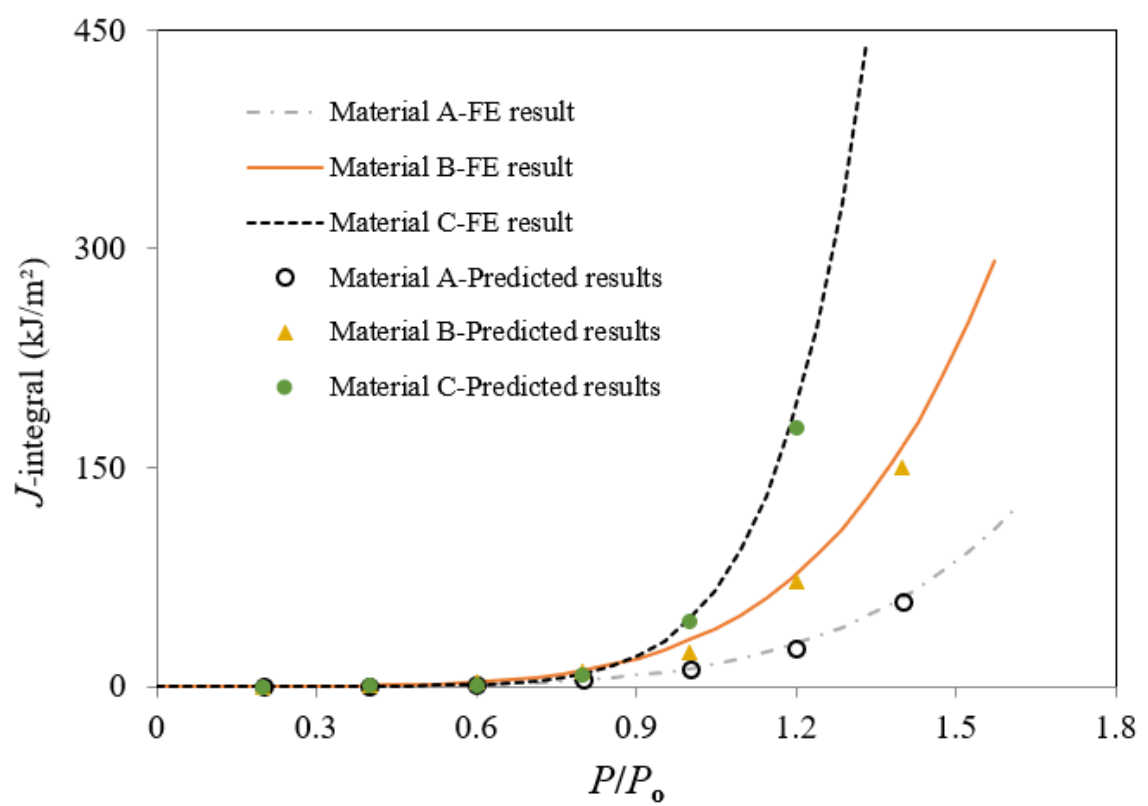

610 Figure 6 Comparison of the elasto-plastic $J$-integrals estimated by Equation (7c) with the FE results based on $\mathrm{R}-\mathrm{O}$ materials for $d / R_{\mathrm{i}}=0.05, a / c=0.6$ and $a / d=0.5$. 


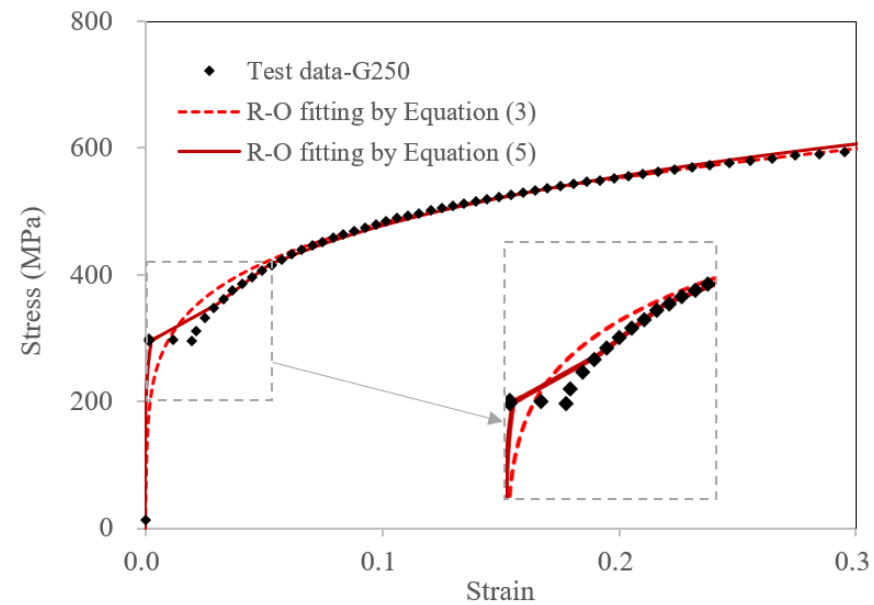

(a)

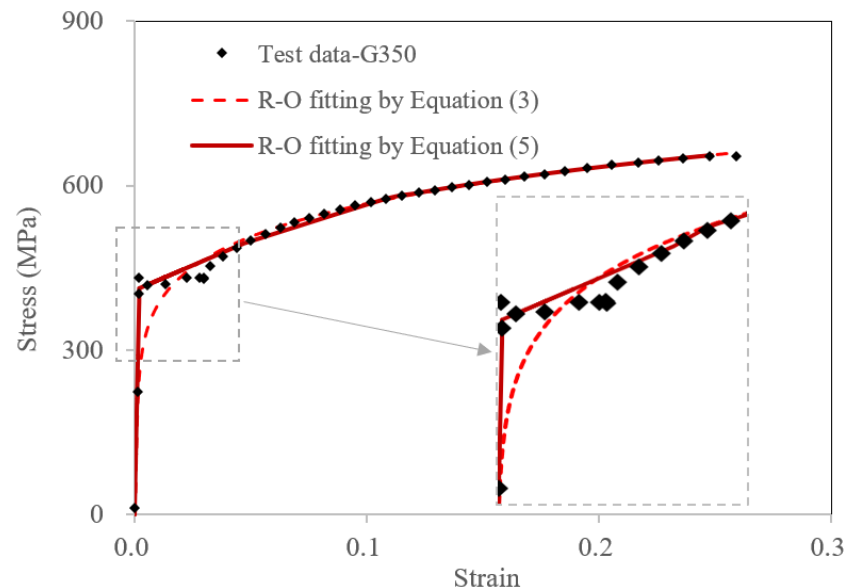

(b)

Figure $7 \quad$ R-O fittings by use of Equation (4) and Equation (6) for steels with yielding plateau for: (a) G250; (b) G350. 


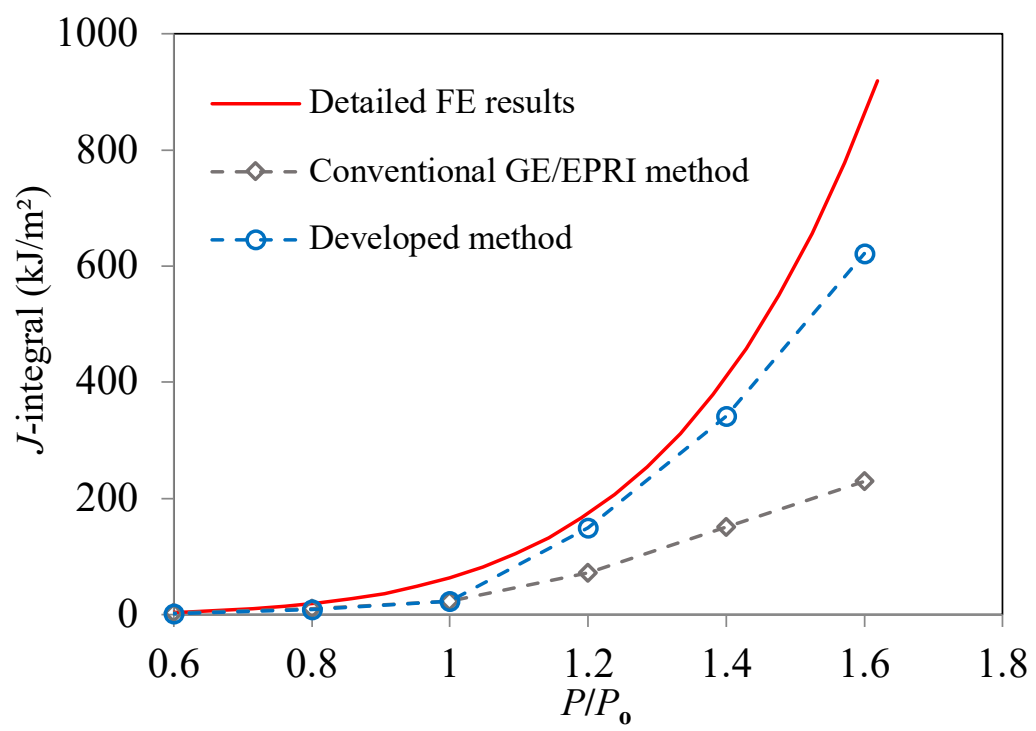

(a)

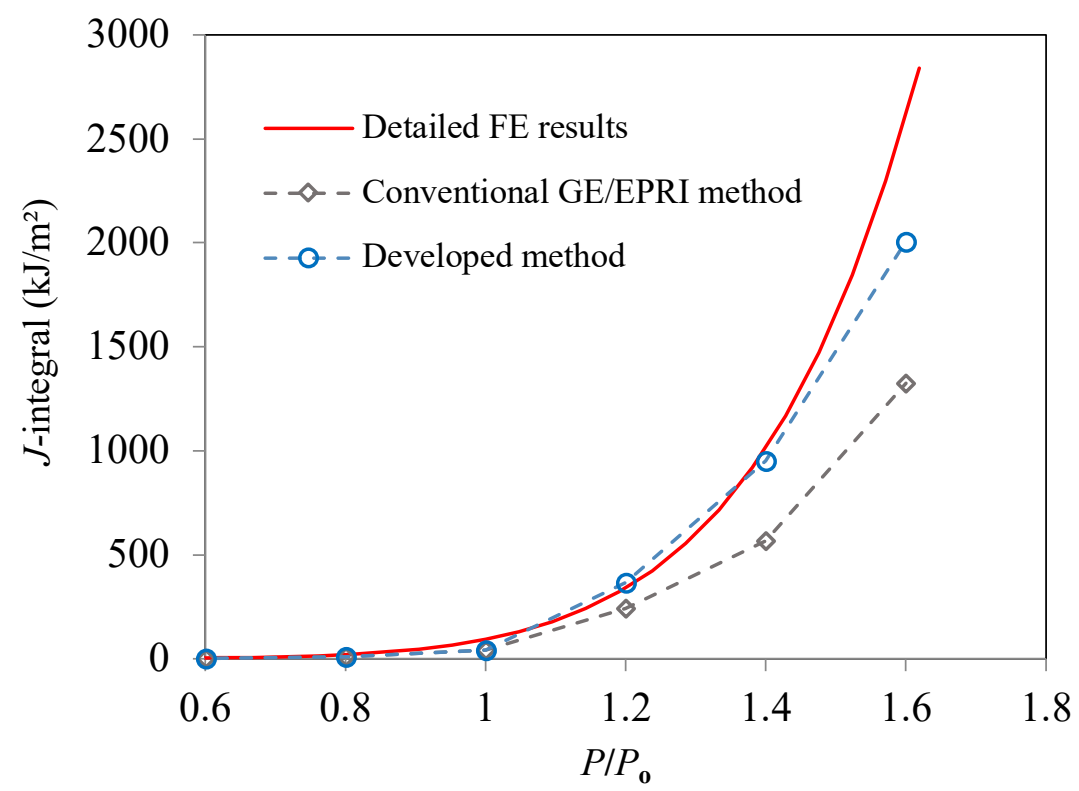

(b)

Figure 8 Comparison of elasto-plastic $J$-integrals determined by the developed method with the detailed FE results for $d / R_{\mathrm{i}}=0.05, a / c=0.6$ and $a / d=0.5$ : (a) G250; (b) G350 


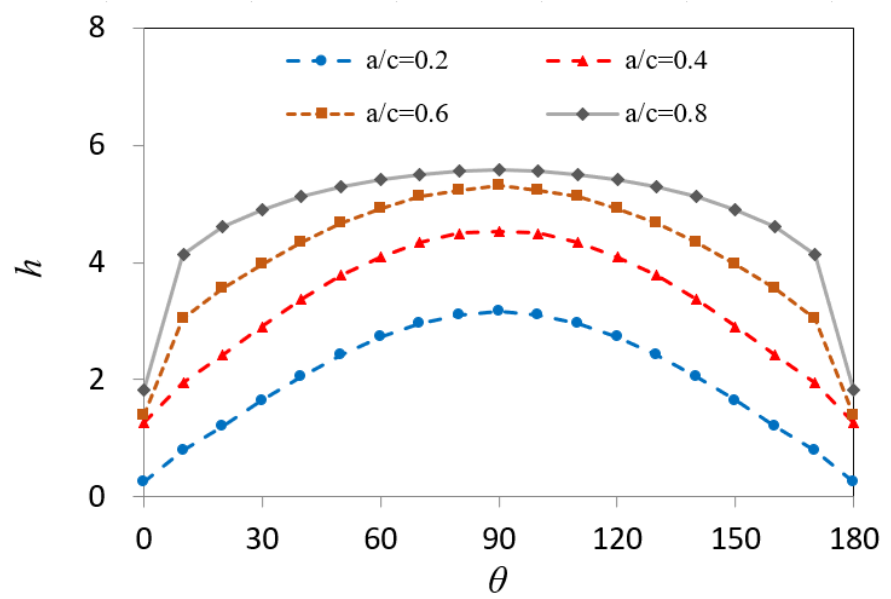

(a)

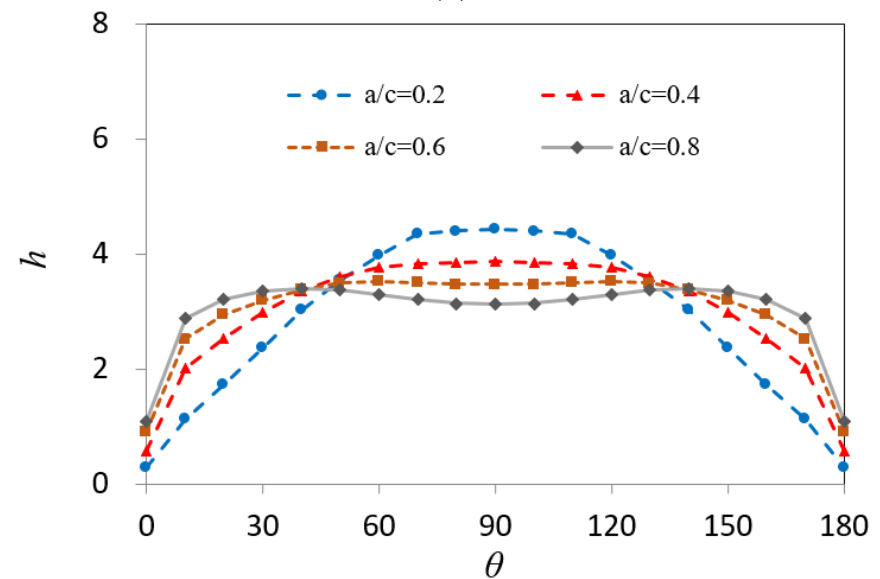

(b)

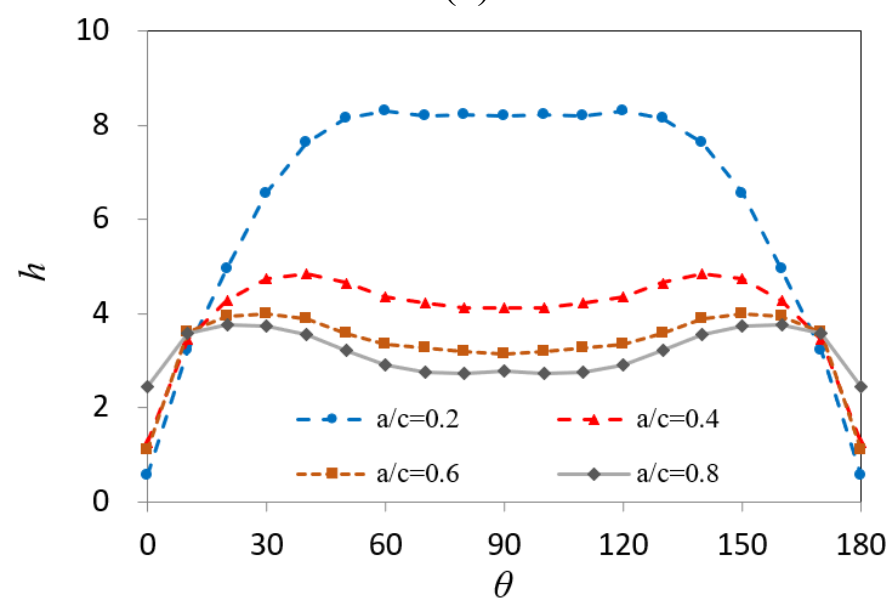

(c)

625 Figure 9 Change of normalised fully plastic $J$-integral values along the whole crack front in cracked pipe with $n=5, d / R=0.1$ and different $a / c$ for: (a) $a / d=0.2$; (b) $a / d=0.5$; (c) $a / d=0.8$ 


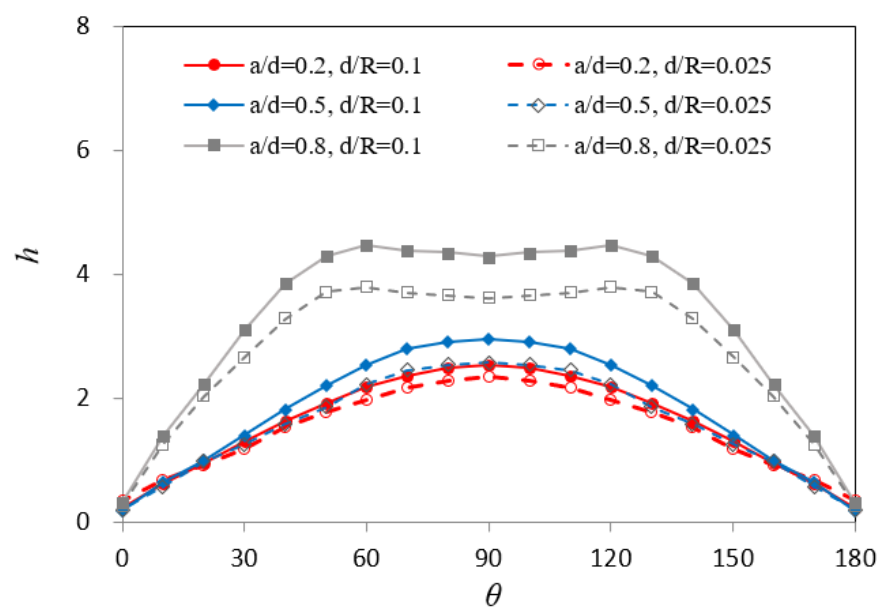

(a)

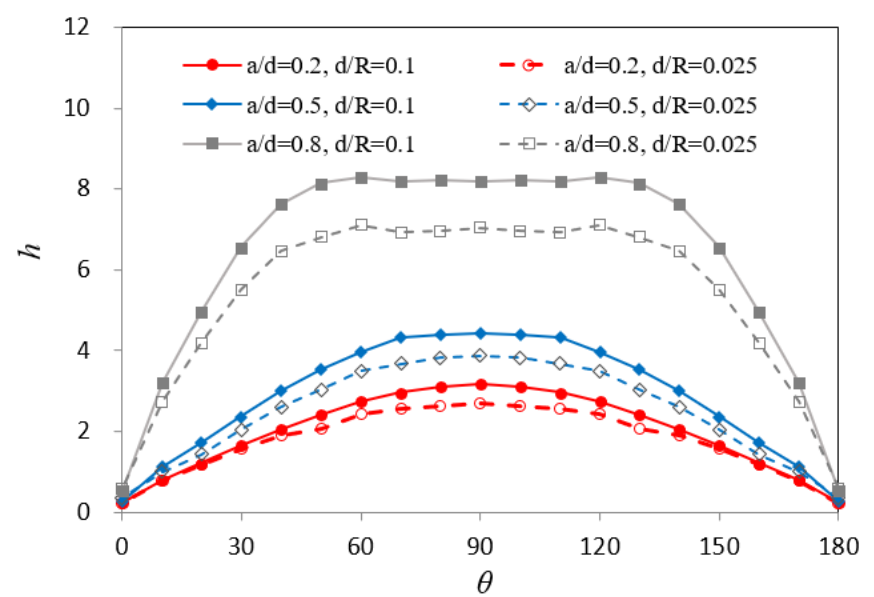

(b)

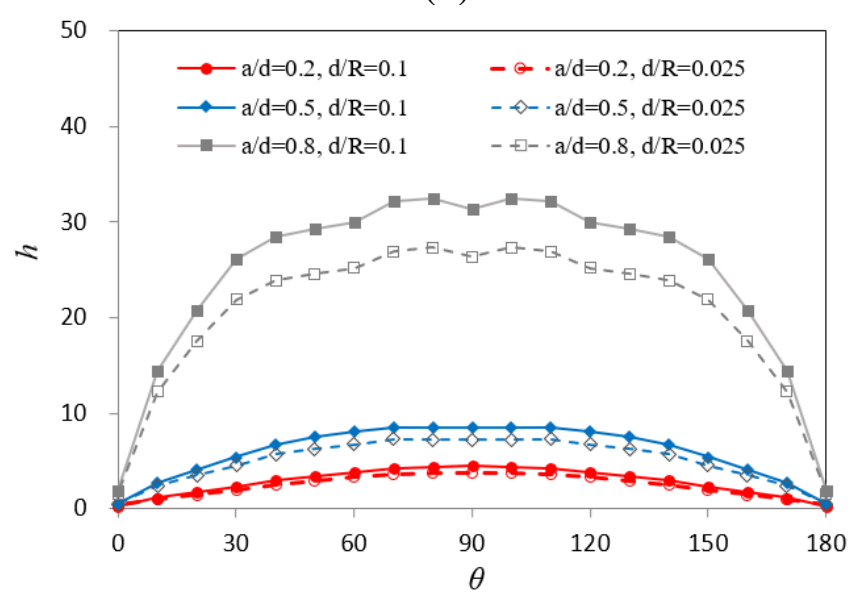

(c)

Figure 10 Change of normalised fully plastic $J$-integral values along the whole crack front in cracked pipe with different $d / R$ and $a / d$ for: (a) $n=3$; (b) $n=5$; (c) $n=10$. 